\title{
Dwarfism, impaired skin development, skeletal muscle atrophy, delayed bone development, and impeded adipogenesis in mice lacking Akt1 and Akt2
}

\author{
Xiao-ding Peng, ${ }^{1,4}$ Pei-Zhang Xu ${ }^{1,4}$ Mei-Ling Chen, ${ }^{1}$ Annett Hahn-Windgassen, ${ }^{1}$ Jennifer Skeen, ${ }^{1}$ \\ Joel Jacobs, ${ }^{1}$ Deepa Sundararajan, ${ }^{1}$ William S. Chen, ${ }^{1}$ Susan E. Crawford, ${ }^{2}$ Kevin G. Coleman, ${ }^{3}$ and \\ Nissim Hay ${ }^{1,5}$ \\ ${ }^{1}$ Department of Molecular Genetics, College of Medicine, University of Illinois at Chicago, Chicago, Illinois 60607, USA; \\ ${ }^{2}$ Department of Pathology, Northwestern University Medical School, Chicago, Illinois 60611, USA; ${ }^{3}$ Pfizer Global Research \\ and Development, Groton, Connecticut 06340, USA
}

To elucidate the functions of the serine/threonine kinase Akt/PKB in vivo, we generated mice lacking both akt1 and akt2 genes. Akt1/Akt2 double-knockout (DKO) mice exhibit severe growth deficiency and die shortly after birth. These mice display impaired skin development because of a proliferation defect, severe skeletal muscle atrophy because of a marked decrease in individual muscle cell size, and impaired bone development. These defects are strikingly similar to the phenotypes of IGF-1 receptor-deficient mice and suggest that Akt may serve as the most critical downstream effector of the IGF-1 receptor during development. In addition, Akt1/Akt2 DKO mice display impeded adipogenesis. Specifically, Akt1 and Akt2 are required for the induced expression of $\operatorname{PPAR} \gamma$, the master regulator of adipogenesis, establishing a new essential role for Akt in adipocyte differentiation. Overall, the combined deletion of Akt1 and Akt2 establishes in vivo roles for Akt in cell proliferation, growth, and differentiation. These functions of Akt were uncovered despite the observed lower level of Akt activity mediated by Akt3 in Akt1/Akt2 DKO cells, suggesting that a critical threshold level of Akt activity is required to maintain normal cell proliferation, growth, and differentiation.

[Keywords: mTOR; 4E-BP1; S6K; TSC2; C/EBP; FKHR/FOXO]

Received February 26, 2003; revised version accepted April 8, 2003.

The serine/threonine kinase Akt, also known as protein kinase $\mathrm{B}(\mathrm{PKB})$, is a downstream effector of phosphatidylinositol 3-kinase (PI3K) and has recently been a focus of intense research. It appears that Akt lies at the crossroads of multiple cellular signaling pathways and acts as a transducer of many functions initiated by growth factor receptors and other receptors that activate PI3K (for review, see Kandel and Hay 1999; Brazil and Hemmings 2001; Lawlor and Alessi 2001). Akt is particularly important in mediating several metabolic actions of insulin. These metabolic activities of Akt have been also implicated in determining cell growth (cell mass) and possibly life span (Finch and Ruvkun 2001; Kozma and Thomas 2002). Another major activity of Akt is to mediate cell survival (Datta et al. 1999; Kandel and Hay 1999). Akt is also frequently activated in human cancers.

${ }^{4}$ These authors contributed equally to this work.

${ }^{5}$ Corresponding author.

E-MAIL nhay@uic.edu; FAX (312) 355-2032.

Article and publication are at http://www.genesdev.org/cgi/doi/10.1101/ gad.1089403.
Three isoforms of Akt (Akt1-Akt3) encoded by three separate genes have been found in mammalian cells. Akt1 is the most ubiquitously expressed isoform in mammalian cells and tissues. Akt2 is also expressed in most tissues and organs, usually at a lower level than Akt1 except in insulin-responsive tissues, where it is expressed at a higher level (Altomare et al. 1995, 1998). Akt 3 is expressed at the lowest level in most adult tissues except testes and brain (Brodbeck et al. 1999; Nakatani et al. 1999). The three isoforms share $>80 \%$ amino acid sequence identity and exhibit the same structural organization. The N-terminal 100 residues possess a pleckstrin homology $(\mathrm{PH})$ domain that binds phospholipids. A short glycine-rich region connects the $\mathrm{PH}$ domain to the catalytic domain and the C-terminal 70 residues that contain a putative regulatory domain. All Akt isoforms are assumed to have identical or similar substrate specificity (Walker et al. 1998).

Akt isoforms are activated via the $\mathrm{PH}$ domain, which binds phosphoinositides (PI) phosphorylated at the D3 position of the inositol ring [PI $(3,4,5) \mathrm{P} 3]$, generated by 
the catalytic subunit of PI3K. Subsequently, Akt is translocated to the plasma membrane, where it is phosphorylated on two residues for full activation. The two residues are Thr 308, which is phosphorylated by PDK1, and Ser 473 in Akt1. Akt is negatively regulated by molecules that antagonize PI3K, such as PTEN (for phosphatase and tensin homolog deleted from Chromosome 10). PTEN, which is mutated or deleted in a wide range of human cancers, is a 3-phosphoinositide phosphatase and thus negatively regulates Akt by reducing the intracellular level of PIP3 generated by PI3K (Cantley and Neel 1999; Simpson and Parsons 2001).

The PI3K/PTEN/Akt signaling pathway is highly conserved from worms to mammals, and its most conserved function is mediating cellular energy metabolism that is coupled to life span in Caenorhabditis elegans (Edgar 1999; Finch and Ruvkun 2001; Britton et al. 2002). In flies (Scanga et al. 2000) and mammals the pathway is also associated with cell survival and inhibition of apoptosis, functions that may also be linked to cellular energy metabolism (Gottlob et al. 2001).

To dissect the functions of Akt in a mammalian organism, mice lacking single Akt isoform were generated. Akt1-null mice display mild growth retardation and increased apoptosis (Chen et al. 2001; Cho et al. 2001b), and the Akt2-null mice are insulin-resistant and display a diabetic phenotype (Cho et al. 2001a; Garofalo et al. 2003). Here, we report the phenotype of mice that are deficient for both Akt1 and Akt2. Akt1/Akt2 doubleknockout (DKO) mice are born alive and exhibit the expected Mendelian distribution of traits, but die shortly after birth. Despite the fact that Akt is a downstream effector of multiple growth factor receptors, Akt1/Akt2 DKO mice display a phenotype that is strikingly similar to that of IGF-1-receptor-deficient mice (Liu et al. 1993). Akt1/Akt2 DKO mice are dwarfs with body weight that is $\sim 50 \%$ less than normal. The most visible phenotype of these mice is translucent skin, caused by impaired proliferation of basal keratinocytes without apparent inhibition of differentiation. The DKO mice exhibit a severe atrophy of skeletal muscles, which is mostly caused by a decrease in individual muscle fiber size. We show that Akt1/Akt2 deficiency impairs the activity of mTOR and the phosphorylation of the repressor of mRNA translation, 4E-BP1 (Gingras et al. 2001), which may explain the reduced muscle fiber size. Like the IGF-1-receptor-defi- cient mice, the Akt1/Akt2 DKO mice also exhibit a developmental delay in ossification of the bones. However, Akt1/Akt2 DKO mice also exhibit a near complete impediment to adipogenesis. The DKO mice lack differentiated brown adipose tissues, and DKO mouse embryo fibroblasts (MEFs) are impaired in their ability to differentiate to adipocytes. We show that Akt is required for the induction of preoxisome proliferating-activated receptor- $\gamma$ (PPAR $\gamma$ ) expression during adipocyte differentiation and thus establish a new essential function for Akt in adipogenesis.

\section{Results}

Dwarfism and neonatal lethality in Akt1/Akt2 DKO mice

To generate mice that are deficient for both Akt1 and Akt2, we first crossed inbred DBA/1lacJ Akt2-null mice (described elsewhere; Garofalo et al. 2003) to Akt1-null mice (Chen et al. 2001) to generate double-heterozygous mice. The Akt2-null mice used in these studies display a diabetic phenotype similar to that of previously reported Akt2-null mice (Cho et al. 2001a; data not shown). The double-heterozygous mice were then intercrossed to generate the DKO mice. In initial analysis of 20 litters recovered from the double-heterozygous mating, we could not recover any DKO mice. However, further analysis revealed that embryonic day 18.5 (E18.5) DKO embryos are alive. Close monitoring of newborns revealed that DKO mice are born alive but die within a few hours after birth. We suspect that the death is caused by respiratory failure, based on our observations that DKO newborns displayed labored breathing. Close monitoring of 19 litters shows that the DKO mice are born in an expected Mendelian distribution, as we did not find that the theoretical and actual rates are statistically different (Table 1). Semiquantitative reverse transcriptase PCR (RTPCR) analysis shows RNA expression of the three akt genes in MEFs with various genotypes, which were derived from the double-heterozygous mating (Fig. 1A). Expression of Akt1 and Akt2 proteins in skeletal muscles derived from E18.5 embryos is shown in Figure 1B. The DKO neonates and E18.5 embryos are severely growthdeficient, with a birth weight $\sim 50 \%$ of that of their wild-type or double-heterozygous (DHet) littermates (Fig. 1C,D).

Table 1. Genotype distribution of newborns ${ }^{a}$ derived from Akt1/Akt2 double-heterozygous mating

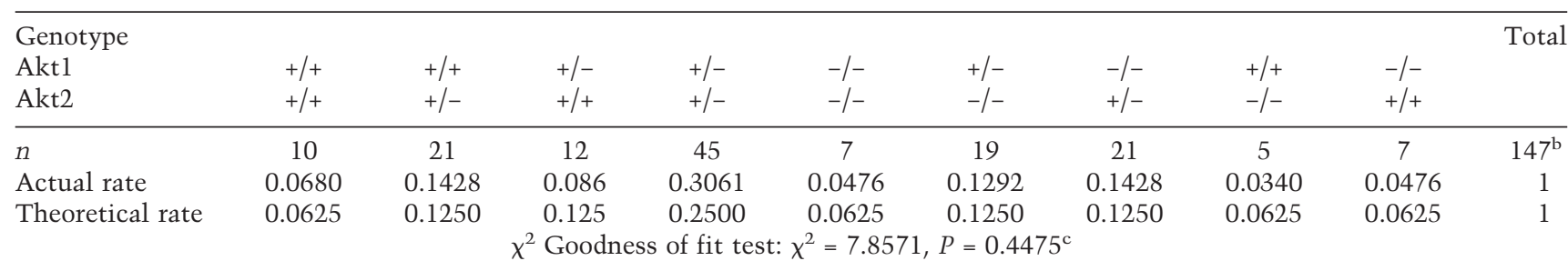

${ }^{a}$ Newborns were collected by putting pregnant female on a metal grid platform prior to delivery.

${ }^{\mathrm{b}}$ From 19 litters of newborns of Akt1/Akt2 double-heterozygous parents.

${ }^{\mathrm{c}}$ There is no significant difference between the actual and theoretical rates. 


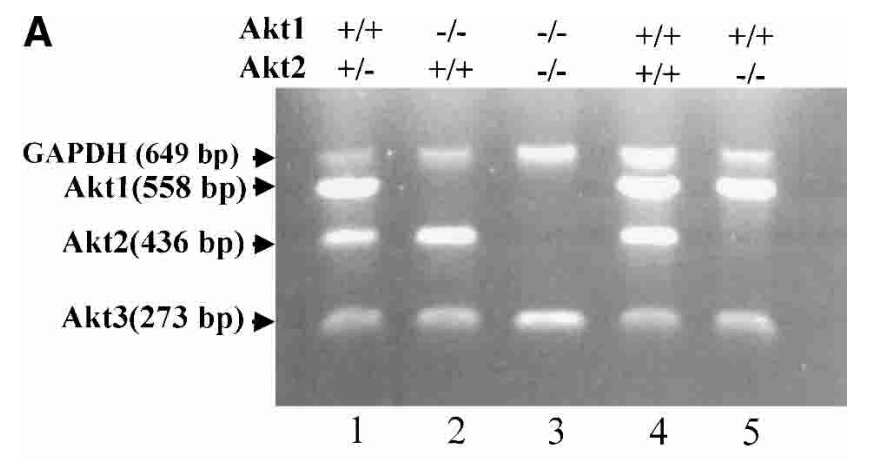

\section{C}
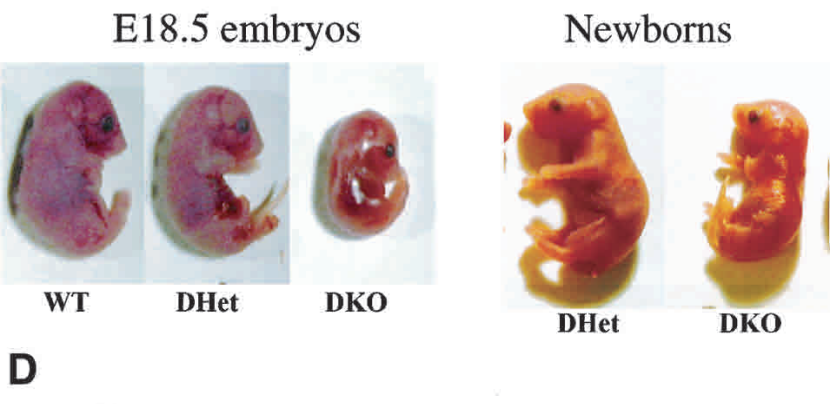

B
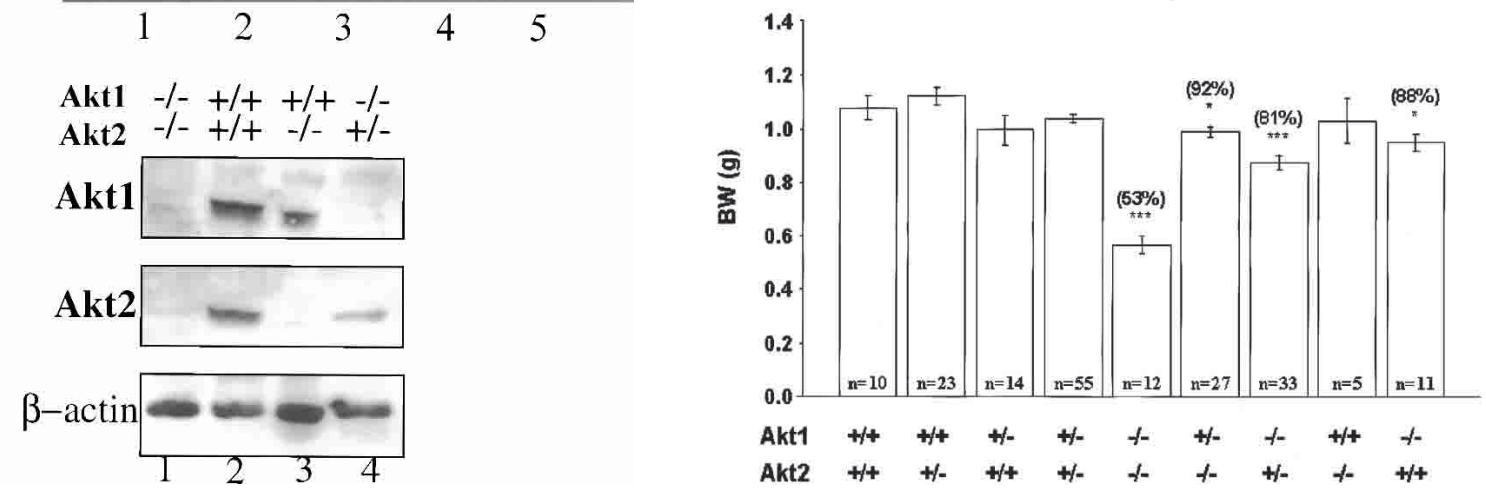

Figure 1. (A) RT-PCR analysis of Akt1, Akt2, and Akt3 RNA expression in mouse embryo fibroblasts (MEFs) of different genotypes derived from double-heterozygous matings. Complementary DNA was amplified by PCR with primers specific for mouse Akt1, Akt2,

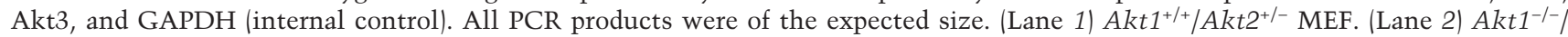

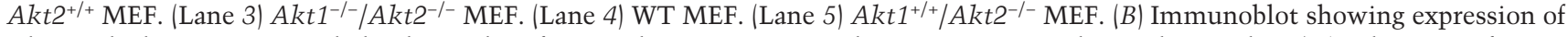
Akt1 and Akt2 proteins in skeletal muscles of WT and mutant E18.5 embryos, using anti-Akt1 and anti-Akt2. (C) Side views of E18.5

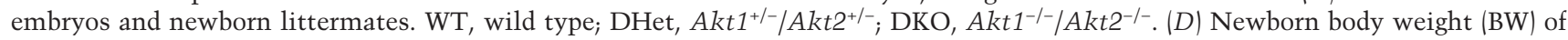
WT and Akt1/Akt2 mutant mice. The relative average BW (percent of mutant to WT newborns) is shown in parentheses. Results are mean \pm S.E.M. ${ }^{\star}, P<0.05 ;{ }^{\star \star \star}, P<0.001$.

These results indicate that Akt1 and Akt2 are not required for successful completion of gestation in the mouse. However, the growth of Akt1/Akt2 DKO embryos and newborns is severely impaired. As was previously shown, the deletion of Akt1 results in mild growth retardation (Chen et al. 2001; Cho et al. 2001b), whereas the deletion of Akt2 was reported not to have an effect on animal size (Cho et al. 2001a). The results shown in Figure $1 \mathrm{C}$ and $\mathrm{D}$, however, clearly demonstrate that the deletion of Akt2 intensified the growth deficiency seen in Akt1-null mice. Furthermore, although we did not observe a significant growth deficiency in Akt2-null mice in a mixed DBA/1lacJxC57Bl/6 background (Fig. 1D), inbred DBA/1lacj Akt2-null mice display mild growth retardation similar to that observed in Akt1-null mice (Garofalo et al. 2003).

\section{Skin development is impaired in Akt1/Akt2 DKO mice}

The most visible phenotype of the DKO neonates and E18.5 embryos is their translucent skin when compared with wild-type (WT) and DHet littermates (Fig. 2A). Histological analysis of the skin layers revealed that the size and the number of hair follicles is markedly decreased, and that the individual skin layers are much thinner in DKO animals (Fig. 2B). Analysis of differentiation-specific markers suggests that all the skin layers are present, indicating that differentiation per se is not blocked (Fig. 2C). However, the number of cells in each of the skin layers is markedly reduced. This is especially profound in the spinous layers stained with anti-keratin 10 and, to some extent, in the granular layer (stained with antifilaggrin) as well as the basal layer (stained with antikeratin 14). Proliferation of the basal keratinocytes is markedly reduced, as evident from the anti-PCNA staining (Fig. 2C). As shown in Figure 2B and C, hair follicle development is severely impaired in DKO mice. Hair follicle development can be divided into four stages (Muller et al. 1991). In stage 1, the hair bud is characterized by an epiblastic proliferation penetrating the mesenchyme. In stage 2, the hair bulb extends and is depressed at the mesenchymal papilla level. Stage 3 is defined by the generation of the hair cone. In stage 4 , the hair comes through the skin surface. In DKO mice, the hair follicles are mainly in stage 1 (hair bud) with a few developing to stage 2 (hair bulb), whereas in WT mice, the hair follicles are fully developed.

Because we have not detected increased apoptosis in the skin by TUNEL assay (data not shown), we speculate 

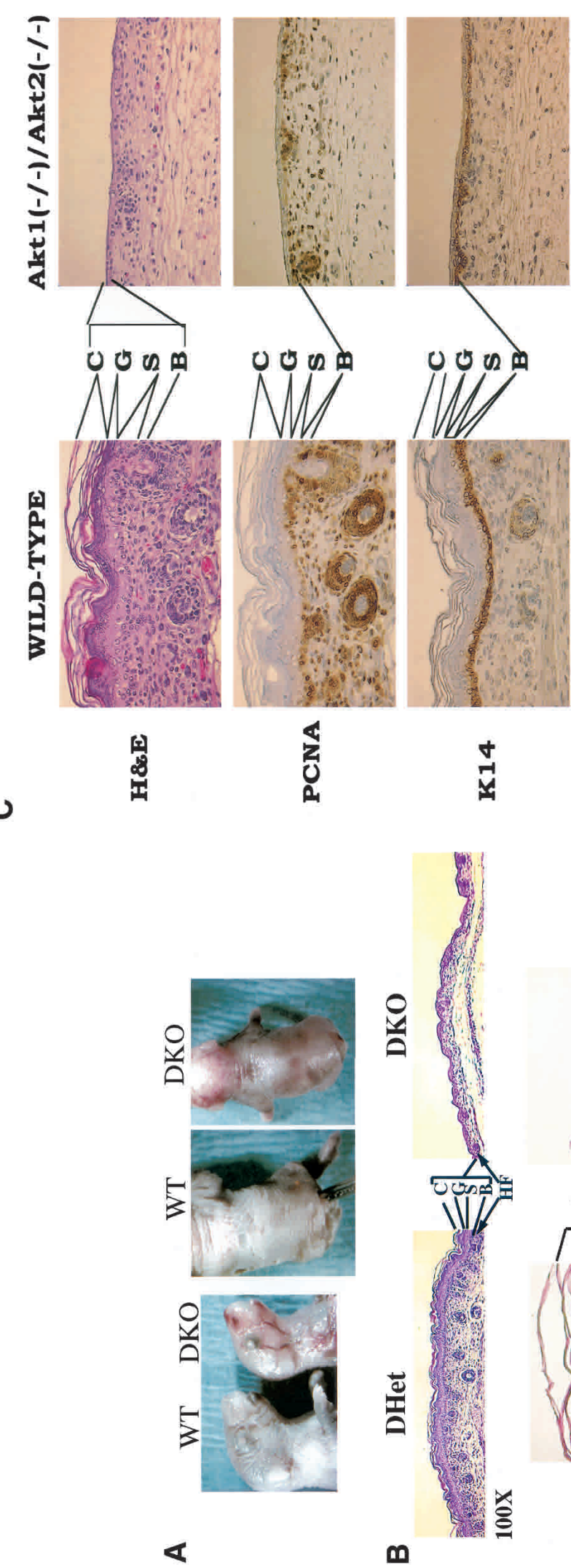

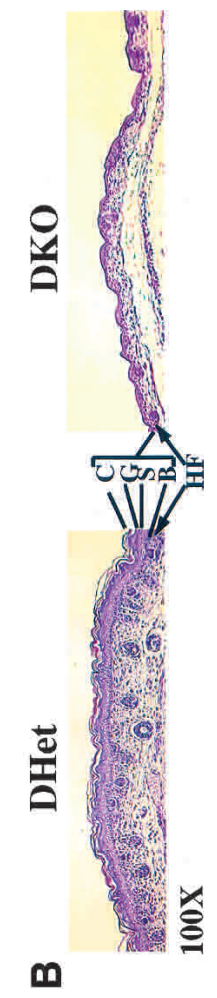

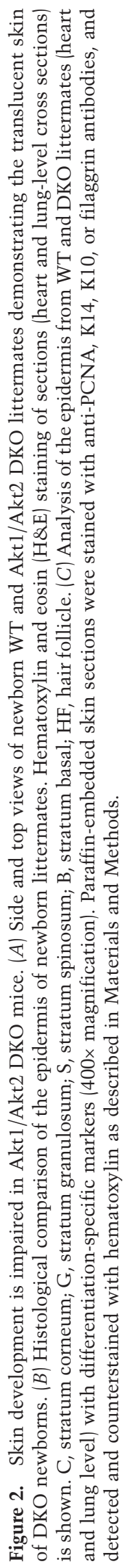


that skin development is impaired primarily as a result of reduced proliferation of the basal keratinocytes. However, we cannot exclude the possibility that this could also be caused by a decrease in epidermal stem cell survival and proliferation. Interestingly, a similar phenotype was reported for the IGF-1 receptor KO mice (Liu et al. 1993), suggesting that Akt is the downstream effector of IGF-1-receptor-mediated proliferation of keratinocytes.

\section{Cellular atrophy of skeletal muscles in Akt1/Akt2 DKO mice}

Histopathological analysis revealed that skeletal muscle tissues in DKO E18.5 embryos and newborns are significantly thinner than those of WT and DHet littermates. This is caused mostly by cellular atrophy, as we did not detect a significant decrease in the number of muscle fibers, at least in the respiratory muscles, whereas the size of individual muscle fibers is markedly decreased (Fig. 3A). Thus, the diaphragm of DKO mice is extremely thin, perhaps accounting for the neonatal respiratory failure and mortality. Compared with WT mice, DKO myofibers are generally smaller, appeared to be more widely spaced, and are arranged in a less compact manner. Calculation of the relative cross-sectional area of individual muscle cells in the diaphragm and presternum (manubrium) as well as the diameter of intercostal muscles revealed that DKO muscle cells are $\sim 50 \%$ smaller than WT cells, and the DHet cells are of intermediate size (Fig. 3B). These results establish genetic evidence that Akt is required for determining cell growth or cell mass of mammalian cells.

\section{mTOR activity is impaired in Akt1/Akt2 DKO cells}

It has been previously shown that cell mass, and particularly skeletal muscle cell mass, is determined by the activity of mTOR (Bodine et al. 2001; Rommel et al. 2001; Fingar et al. 2002; Pallafacchina et al. 2002), and we have previously placed Akt upstream of mTOR (Gingras et al. 1998). The ability of mTOR to regulate cell size may be dependent on its downstream effectors, the 4E-binding protein (4E-BP1) and p70S6 kinase (S6K1), that regulate protein synthesis (Dufner and Thomas 1999; Gingras et al. 2001). S6K1 is a positive regulator of protein synthesis, and its activity is induced by mTOR-mediated phosphorylation. The repressor of mRNA translation, 4E$\mathrm{BP} 1$, binds to the initiation factor $4 \mathrm{E}$ for eukaryotic translation (eIF4E) and inhibits its activity. Phosphorylation of 4E-BP1 in an mTOR-dependent manner inhibits its binding to eIF4E and accelerates protein synthesis (Gingras et al. 1999, 2001). Thus, to determine whether the DKO cells are impaired in the activity of mTOR, we examined the phosphorylation of its downstream effectors, 4E-BP1 and p70S6K (S6K1), as readouts for mTOR activity.

We first examined the steady-state level of phosphorylation of 4E-BP1 and S6K1 in proliferating WT and DKO MEFs, using anti-phospho-Ser65 of 4E-BP1 and antiphospho-Thr 389 of S6K1 antibodies. As shown in Figure 4A, lanes 1 and 2, there is a marked reduction in both 4E-BP1 and S6K1 phosphorylation in DKO cells. The reduction in 4E-BP1 phosphorylation is also manifested by the mobility shift using anti-4E-BP1 antibodies. In proliferating WT MEFs, the predominant form of 4E-BP1 is the slower migrating, hyperphosphorylated form, whereas in DKO cells the faster migrating, hypophos-
Figure 3. Skeletal muscle atrophy in Akt1/Akt2 DKO mice. (A) Images of standard H\&E-stained diaphragms from WT, DHet, and DKO E18.5 littermate embryos (630× magnification). (B) Histograms showing the size and diameter of muscle cells. Digitized images of skeletal muscles were analyzed as described in Materials and Methods. Results are mean \pm S.E.M., expressed as the number of pixels in cross-sectional areas of diaphragm and presternum muscle cells or within the width of intercostal muscles. Twenty cells in three random fields were analyzed for each. $P<0.05$.
A

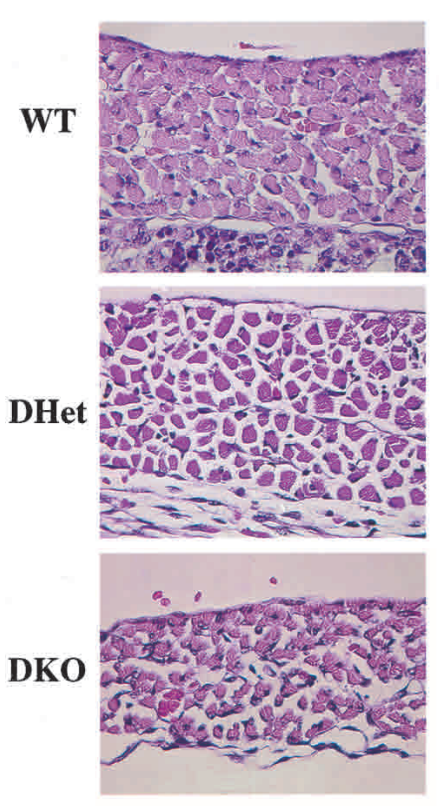

B
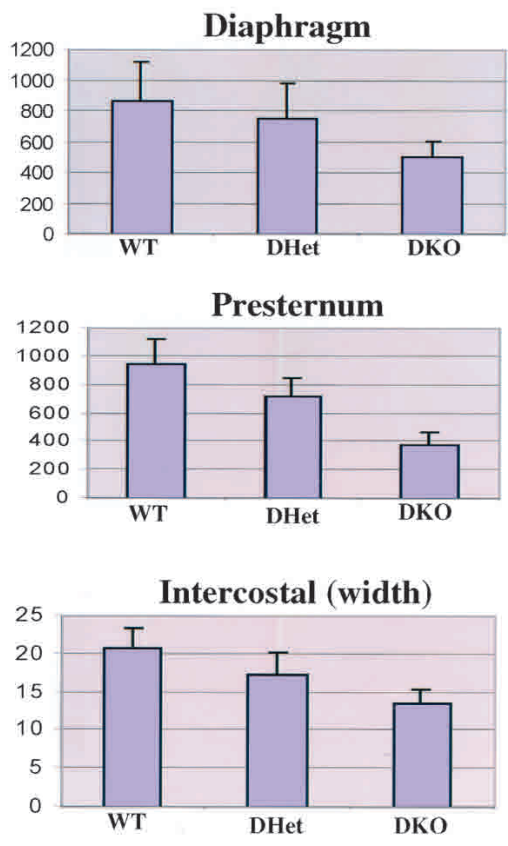
A

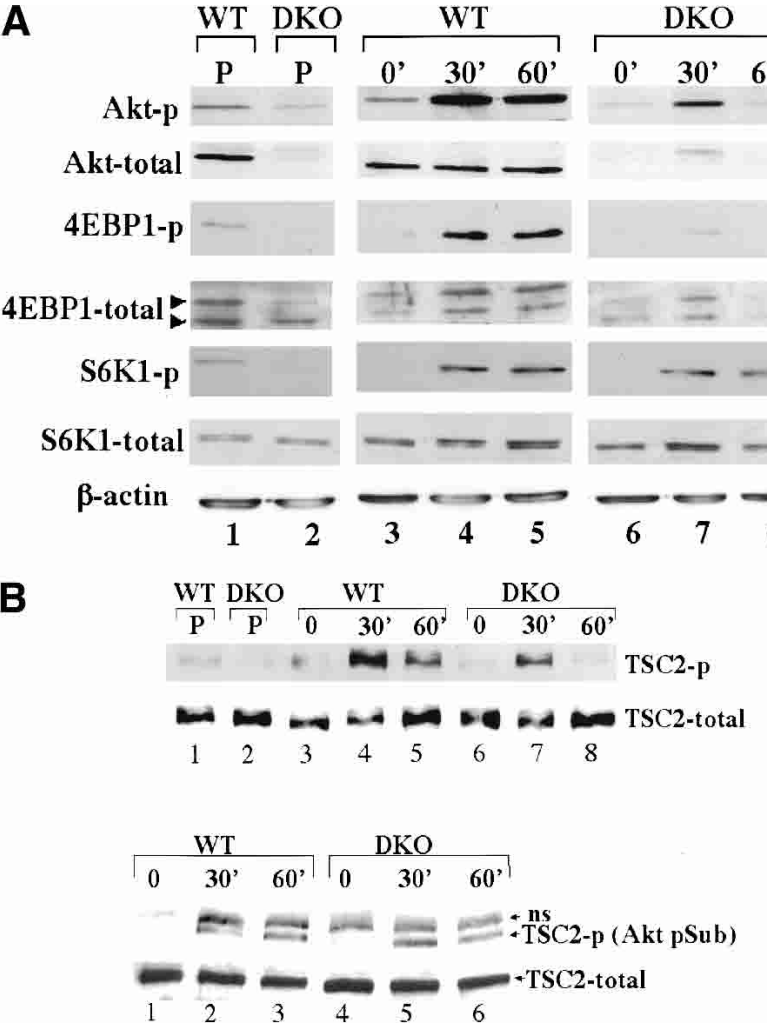

Figure 4. mTOR activity in WT and DKO MEFs. (A) Phosphorylation and protein levels were determined by immunoblotting. (Lanes 1,2) Proliferating $(\mathrm{P})$ cells (passage 4) were plated in $10 \%$ FCS and analyzed $24 \mathrm{~h}$ after plating. (Lanes 3,6) Cells were plated in $10 \%$ FCS for $24 \mathrm{~h}$, then deprived of serum and analyzed $24 \mathrm{~h}$ later. (Lanes 4,5,7,8) After $24 \mathrm{~h}$ of serum deprivation, cells were stimulated with $20 \%$ FCS for 30 and $60 \mathrm{~min}$, respectively. Protein extracts from proliferating, serum-deprived, or serum-stimulated cells were subjected to immunoblotting using anti-phospho-Ser 473 of Akt (Akt-p), anti-panAkt (Akt-total), anti-phospho-Ser 65 of 4E-BP1 (4E-BP1-p), anti4E-BP1 (4E-BP1-total), anti-phospho-Thr 389 of S6K1 (S6K1-p), anti-S6K1 (anti-S6K1), or anti- $\beta$-actin (loading control). (B, top panel) TSC2 phosphorylation was determined by immunoblotting using anti-phospho-Thr 1452 of TSC2. (Bottom panel) Immunoprecipitation with anti-TSC2 followed by immunoblotting with anti-Akt-p-S/T substrate. ns, nonspecific band. (Lanes 1,4) Cells were plated in 10\% FCS for $24 \mathrm{~h}$ and then deprived of serum and analyzed $24 \mathrm{~h}$ later. (Lanes $2,3,5,6)$ After $24 \mathrm{~h}$ of serum deprivation, cells were stimulated with $20 \%$ FCS for 30 and $60 \mathrm{~min}$, prior to analysis.

phorylated form is predominant (Fig. 4A, lanes 1,2). In addition, we examined 4E-BP1 and S6K1 phosphorylation following serum stimulation of WT and DKO MEFs (Fig. 4A, lanes 3-8). Cells were deprived of serum for 24 $\mathrm{h}$ and then were stimulated with $20 \%$ FCS for 30 and 60 min. As evident from the immunoblot analysis (Fig. 4A, lanes $3-8$, DKO cells are severely impaired in their ability to phosphorylate $4 \mathrm{E}-\mathrm{BP} 1$ upon serum stimulation. However, in these conditions, the phosphorylation of S6K1 is not impaired, suggesting that the threshold of Akt activity required for S6K1 phosphorylation is rela- tively low, compared with that required for 4E-BP1 phosphorylation. Alternatively, it is possible that other kinases may substitute for Akt-mediated phosphorylation of Thr 389 of S6K1 upon serum stimulation. Indeed, it has been recently reported that PDK1 and PKC $\zeta$ are able to mediate Thr 389 phosphorylation in an mTOR-independent manner (Romanelli et al. 2002). Taken together, these results establish genetic evidence that Akt is required for mTOR activity in mammalian cells.

Akt may affect mTOR activity through the direct phosphorylation of tuberous sclerosis complex-2 (TSC2; Inoki et al. 2002; Manning et al. 2002; Potter et al. 2002). We therefore examined the phosphorylation status of TSC2 in Akt1/Akt2 DKO MEFs before and after serum stimulation. Using the anti-phospho-Thr 1452 of TSC2 antibodies (Manning et al. 2002), we found reduction in TSC2 phosphorylation in DKO cells (Fig. 4B, upper panel). However, this reduction is not directly correlated with the reduced phosphorylation of 4E-BP1. The extent of Thr 1452 phosphorylation of TSC2 60 min after serum stimulation in WT cells is comparable to that observed 30 min after serum stimulation in DKO cells (Fig. 4B, upper panel, lanes 5,7). However, the phosphorylation of 4E-BP1 is significantly reduced $30 \mathrm{~min}$ after serum stimulation in DKO cells when compared with that observed 60 min after serum stimulation in WT cells (Fig. 4A, lanes 5,7). Moreover, following serum stimulation in DKO cells, immunoprecipitation with anti-TSC2 antibodies followed by immunoblotting with an anti-Akt-pS/T substrate-antibody shows only a slight, and occasionally insignificant, reduction in TSC2 phosphorylation when compared with that observed in WT cells (Fig. $4 \mathrm{~B}$, lower panel; data not shown). In contrast, 4E-BP1 phosphorylation is significantly and consistently diminished in DKO cells (Fig. 4A; data not shown). These results suggest, first, that a relatively low level of Akt activity is required to phosphorylate TSC2; and second, that Akt can affect 4E-BP1 phosphorylation and probably mTOR activity also through an additional mechanism that is independent of TSC2 phosphorylation (see Discussion).

Interestingly, we observed compensation for the deletion of Akt1 and Akt2 in DKO cells. First, 4E-BP1 expression is consistently reduced in DKO cells (Fig. 4). This phenomenon most likely reflects the inefficient phosphorylation of 4E-BP1 in these DKO cells, which would have the net effect of inhibiting translation. Thus, 4E-BP1 down-regulation would enhance mRNA translation. Second, total Akt activity, as measured by Ser 473 phosphorylation, is not always proportionally reduced in DKO cells. We estimate that in WT MEFs, Akt3 expression comprises $\sim 10 \%$ of the total Akt expression (Fig. 1A, lane 4). Accordingly, Akt protein cannot be readily detected in DKO cells, using anti-pan-Akt antibodies (Akt-total, Fig. 4, lanes 2,6-8). However, Ser 473 phosphorylation can still be detected in DKO cells and is not reduced to $10 \%$ of that of WT cells (Fig. 4A, lanes 1,2). This could be because of enhanced signaling upstream of Akt3 to compensate for the loss of Akt activity in DKO cells. However, we cannot fully exclude the possibility 
that, despite a lower level of expression, Akt3 is inherently more active than Akt1 or Akt2.

\section{Delayed bone development in Akt1/Akt2 DKO mice}

The dwarfism, neonatal lethality, impaired skin development, and skeletal muscle atrophy observed in Akt1/ Akt2 DKO mice is a phenocopy of the defects observed in IGF-1-receptor-deficient mice (Liu et al. 1993). Because IGF-1-receptor-deficient mice also exhibit delayed ossification, we analyzed ossification in Akt1/Akt2 DKO embryos and neonates. For analysis of ossification, skeletons of Akt1/Akt2 DKO embryos and neonates and their DHet and WT littermates were subjected to double staining with alcian blue (stains cartilaginous regions) and alizarin red S (stains ossified regions; Fig. 5; Menegola et al. 2001). In E14.5 embryos, the onset of ossification is observed in the head skeleton, axial skeleton, and limbs of WT and DHet skeletons, whereas ossification can hardly be detected in the DKO skeleton, in particular, the head skeleton. When ossification is almost completed in WT and DHet E18.5 embryos and neonates, large cartilaginous regions in the cranium, axial skeleton, and limbs are observed in the DKO skeleton (Fig. $5 \mathrm{~A}, \mathrm{~B})$. Thus, the delayed bone ossification observed here is also similar to the reported phenotype of IGF-1 receptor KO mice (Liu et al. 1993).

\section{Adipocyte differentiation is blocked in Akt1/Akt2 DKO mice and cells}

Another profound phenotype of the DKO neonates and E18.5 embryos was revealed through histological analy- sis of brown adipose tissues (BATs). Wild-type BATs stained with $\mathrm{H} \& \mathrm{E}$ are visualized as large pads composed of cells with eosinophilic cytoplasm containing numerous lipid droplets and a small spherical nucleus located in the center. In contrast, the thin DKO BAT pad is composed of a relatively small number of small basophilic polygonal cells with barely visible fine vesicles in the cytoplasm and relatively large nuclei (Fig. 6A,B). In WT neonates and E18.5 embryos, adipocyte differentiation can be clearly observed, as the vast majority of the cells are filled with lipid droplets and only a few cells are stained with anti-PCNA (Fig. 6B). In marked contrast to WT newborns and E18.5 embryos, we could not observe cells with lipid droplets in DKO mice, and most of the DKO preadipocytes were found in a proliferative state, as indicated by the anti-PCNA staining (Fig. 6A,B). The BATs of DHet littermates display an intermediate phenotype (Fig. 6A,B). This phenotype was found in all examined BAT tissues.

TUNEL assays did not provide any evidence of increased apoptosis in DKO BAT tissues (data not shown), indicating that the observed phenotype is not due to increased apoptosis of preadipocytes.

The requirement of Akt for adipocyte differentiation could be reproduced in vitro through the induction of adipocyte differentiation in cultured MEFs. MEFs were subjected to adipocyte differentiation as previously described (Miki et al. 2001), using 3-isobutyl-1-methylxanthine, dexamethasone, and insulin (IBMX/DEX/INS), and then were stained with Oil-Red-O to detect lipid droplets. As shown in Figure 7A, WT MEFs can readily differentiate to adipocytes, whereas DKO MEFs cannot. The extent of differentiation was quantified by the Oil-
Figure 5. Bone development in WT, DHet, and DKO embryos. (A) Whole skeletons of E14.5 and E18.5 embryos and newborns (NB) were analyzed for ossification using alcian blue and alizarin red. Ossification is visible in the cranium of E14.5 WT and DHet embryos but not in the cranium of E14.5 DKO embryos. Ossification is nearly complete in WT and DHet newborns, whereas large cartilaginous regions are still present in the cranium and skeleton of DKO newborns. (B) Top view of the cranium (top panel) and side view of the hind limb (bottom panel) of WT and DKO newborns showing cartilaginous regions in the interparietal, exoccipital, and surpraoccipital areas (top panel) and in the femur, tibia, and fibula (bottom panel).

\section{A \\ E14.5}

E18.5

DKO

DHet WT
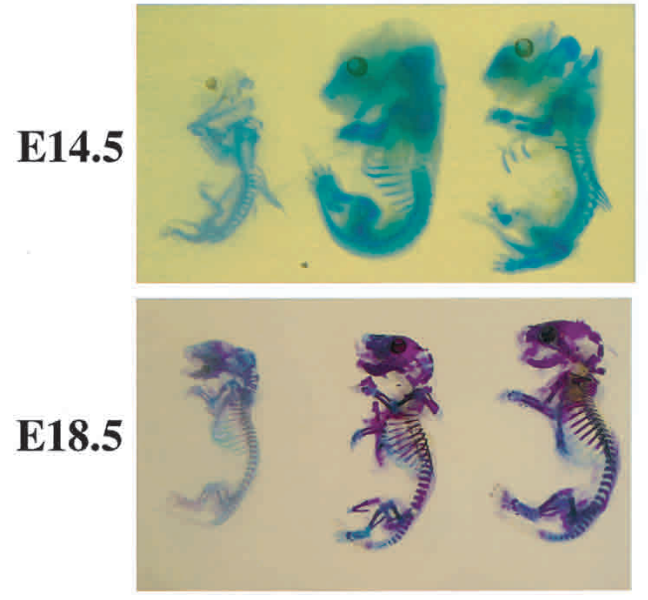

NB

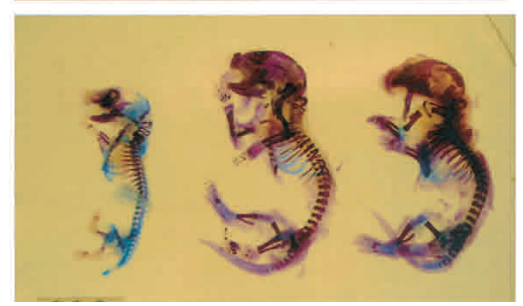

B

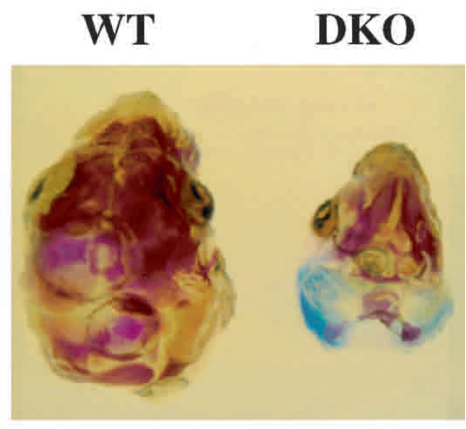

WT

DKO

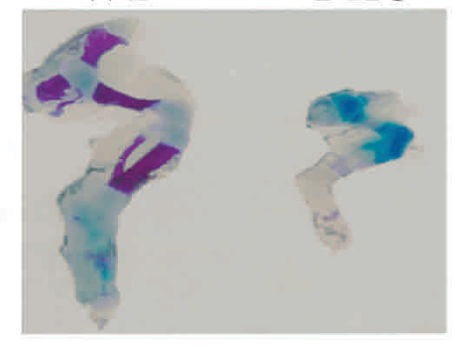


A

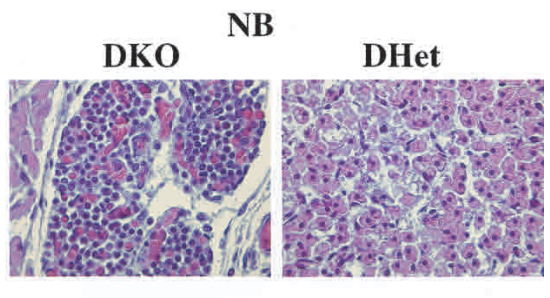

B

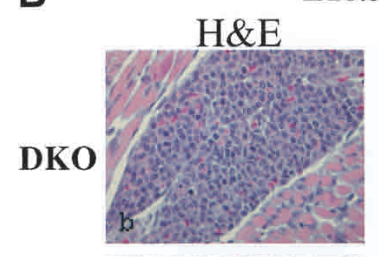

E18.5

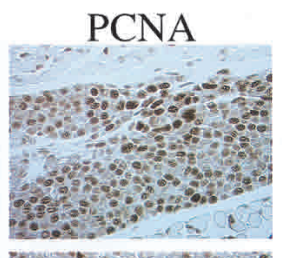

Figure 6. Impaired adipogenesis in Akt1/Akt2 DKO mice. $(A)$ $\mathrm{H} \& \mathrm{E}$-stained cross sections of the dorsal fat pad at heart level of DHet and DKO newborn littermates (400x magnification). (B) Cross sections of the dorsal fat pad at heart level of E18.5 WT, DHet, and DKO littermates. (Left panels) H\&E staining. (Right panels) Staining with anti-PCNA (400× magnification).

Red-O staining (Fig. 7B,C). Although DKO MEFs showed increased susceptibility to apoptotic stimuli (data not shown), we have not observed significantly more apoptosis in DKO cells upon induction of differentiation, suggesting that the impaired differentiation observed in DKO cells is not due to an increase in apoptosis. Taken together, these results established genetic evidence that Akt is absolutely required for adipocyte differentiation.

It was previously shown that Akt2 is highly expressed in embryonic BAT (Altomare et al. 1998). However, Akt1 is the predominantly expressed isoform in MEFs (Fig. 1A), and deletion of Aktl severely impairs adipocyte differentiation in vitro, as determined by Oil-Red-O staining (Fig. 7C). The deletion of Akt2 in MEF has only a modest effect on adipocyte differentiation (Fig. 7C). In contrast, in BAT, where the expression of Akt2 is higher than Akt1, Akt2 contributes more significantly, as seen in the analyses of the individual Akt1 and Akt2 KOs and $\mathrm{Akt1}^{-/-} \mid \mathrm{Akt2}^{+/-}$and $\mathrm{Akt1^{+/- }} / \mathrm{Akt2^{-/- }}$ neonates and E18.5 embryos (data not shown). These results suggest that Akt1 and Akt2 overlap functionally and that their relative level of expression in certain tissues determines the observed phenotype in the mouse (see also Discussion).

Akt is required for the induction of PPARy expression during adipocyte differentiation

To investigate the requirement of Akt for adipocyte differentiation, we first analyzed the expression of preoxisome proliferator-activated receptor $\gamma(\operatorname{PPAR} \gamma)$, which is the key regulator of adipocyte differentiation. PPAR $\gamma$ is induced prior to the transcriptional activation of most adipocyte-specific genes, and ectopic expression of PPAR $\gamma$ in fibroblasts is sufficient to initiate adipocyte differentiation (Tontonoz et al. 1994; Hu et al. 1995; Rosen and Spiegelman 2001). Furthermore, PPAR $\gamma$ is required for adipocyte differentiation, in vivo and in vitro, and PPAR $\gamma$-deficient MEFs fail to differentiate into adipocytes (Barak et al. 1999; Kubota et al. 1999; Rosen et al. 1999|. In WT MEFs treated with IBMX/DEX/INS to induce differentiation, PPAR $\gamma$ expression is initiated $2 \mathrm{~d}$ after onset of differentiation and is further elevated on days 5 and 8 (Fig. 7D, lanes 1,3,5,7). In contrast, PPAR $\gamma$ expression is not elevated in DKO MEFs during this time period (Fig. 7D, lanes 2,4,6,8).

The expression of PPAR $\gamma$ and adipocyte differentiation in culture are also dependent on members of the CAAT/ enhancer-binding protein (C/EBP) family (Rosen et al. 2000). We therefore examined the expression of C/EBPs RNA following addition of IBMX/DEX/INS. We first analyzed the expression of $\mathrm{C} / \mathrm{EBP} \alpha$, which is also required for adipocyte differentiation. As shown in Figure $7 \mathrm{D}$, the expression of $\mathrm{C} / \mathrm{EBP} \alpha$ is also reduced in $\mathrm{DKO}$ MEFs, albeit to a lesser extent than that of PPAR $\gamma$. There is reciprocal regulation of PPAR $\gamma$ and $\mathrm{C} / \mathrm{EBP} \alpha$, and it was shown that deletion of PPAR $\gamma$ reduces $\mathrm{C} / \mathrm{EBP} \alpha$ expression following induction of differentiation (Rosen et al. 2002). Thus, the reduction in C/EBP $\alpha$ expression may be a consequence of the inability of DKO cells to induce PPAR $\gamma$ (see Discussion).

The transcriptional induction of $\mathrm{C} / \mathrm{EBP} \alpha$ and PPAR $\gamma$ during adipocyte differentiation in culture was shown to be dependent on C/EBP $\beta$ and C/EBP $\delta$ (Tanaka et al. 1997). Thus, C/EBP $\beta$ and C/EBP $\delta$ expression was analyzed following induction of differentiation. The time of onset and level of C/EBP $\beta$ and C/EBP $\delta$ expression in DKO cells (Fig. 7E, lanes $2,4,6,8$ ) is comparable to that in wild-type cells (Fig. 7E, lanes 1,3,5,7), with only a slight reduction in C/EBP $\beta$ expression. These results suggest that Akt is exclusively required for the induction of PPAR $\gamma$ expression during adipocyte differentiation but is not required for $\mathrm{C} / \mathrm{EBP} \beta$ and $\mathrm{C} / \mathrm{EBP} \delta$ expression. This is also supported by the observation that impairment of differentiation in PPAR $\gamma$-null MEFs is similarly characterized by an accompanying decrease in C/EBP $\alpha$ expression and with no significant effect on C/EBP $\beta$ and C/EBPS RNA expression (Kubota et al. 1999). In an attempt to determine why C/EBP $\beta$ and C/EBP $\delta$ cannot induce the expression of PPAR $\gamma$, we examined the expression of CHOP10, which dimerizes with C/EBP $\beta$ and C/EBP $\delta$ and inhibits their activity (Ron and Habener 1992). The transcriptional activity of C/EBP $\beta$ and C/EBP $\delta$ is dependent, to some extent, on the down-regulation of CHOP10 upon induction of differentiation. We 
Peng et al.

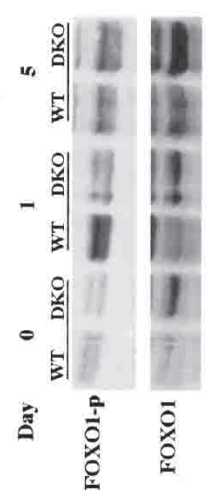

丩

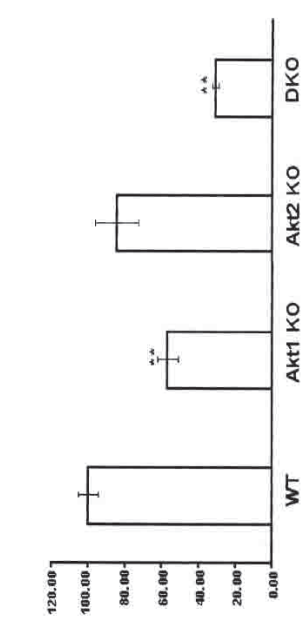

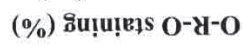

0

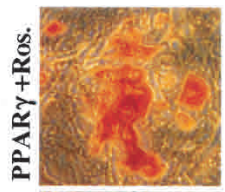

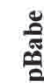

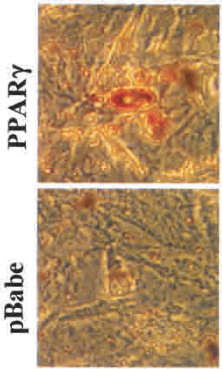

$\circlearrowleft$

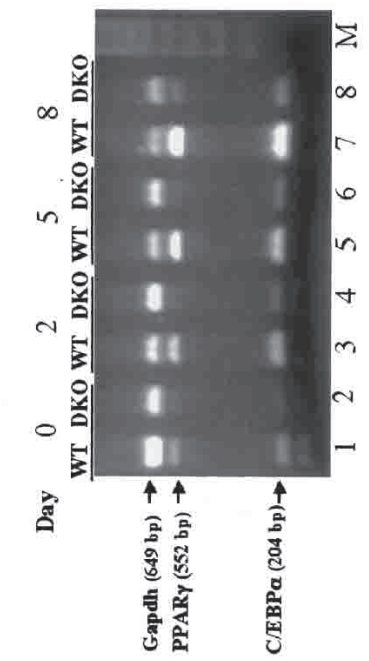

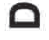

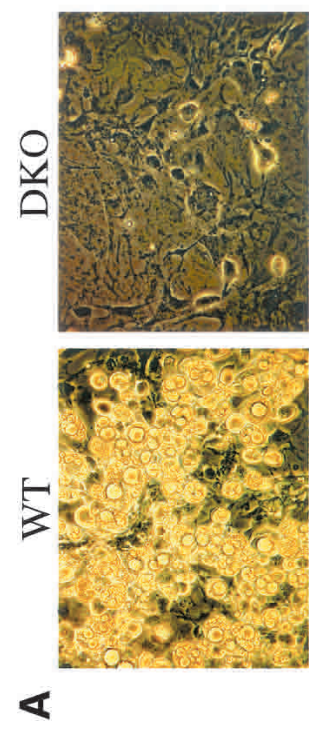

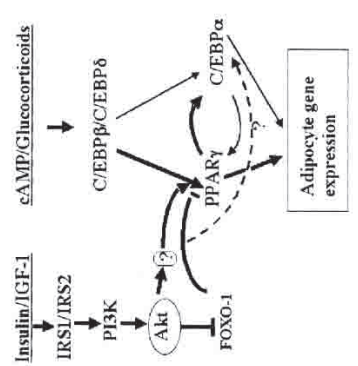

I

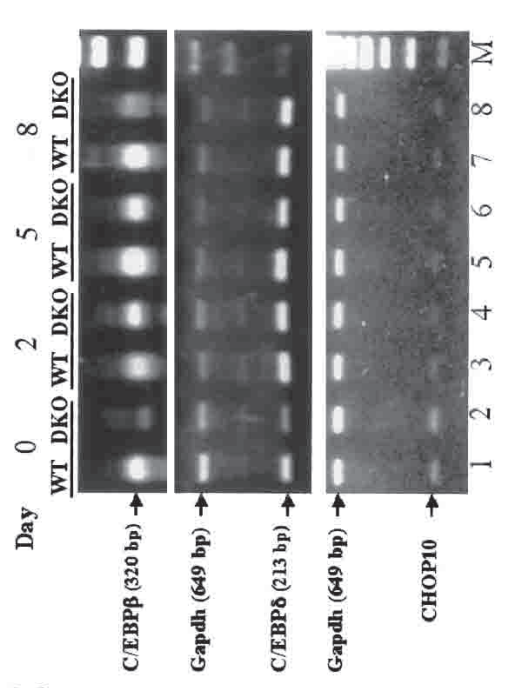

U

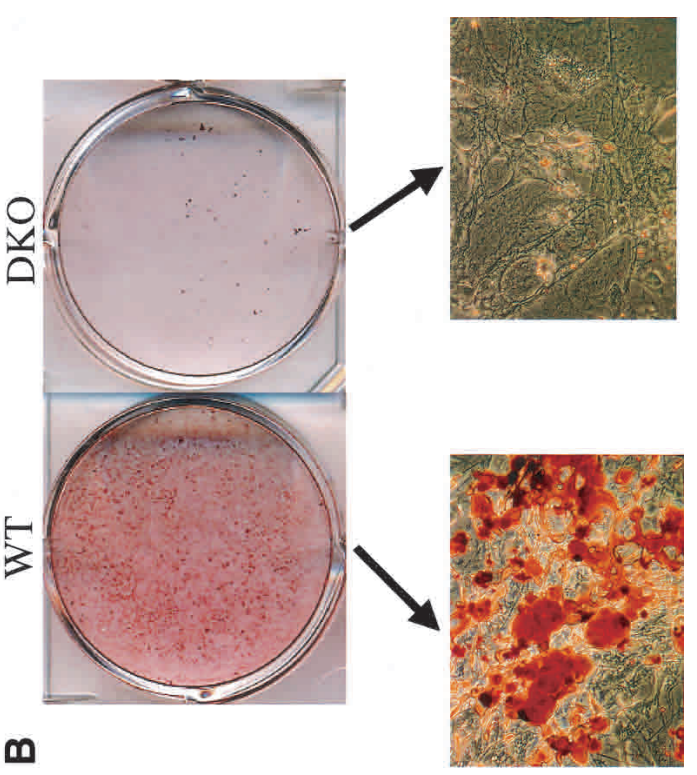

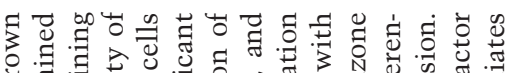

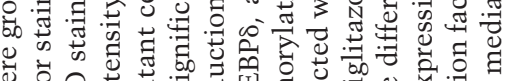

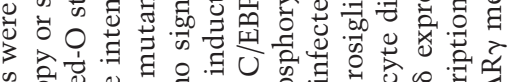
o 숭

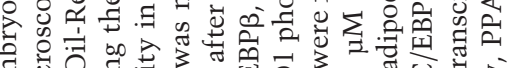

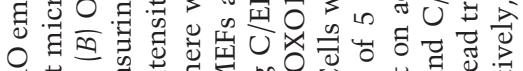

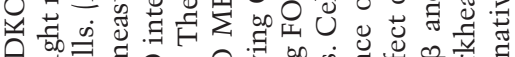

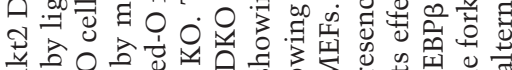

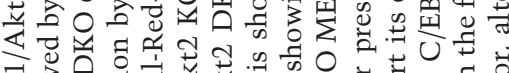

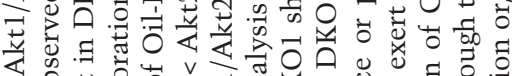

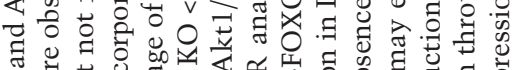

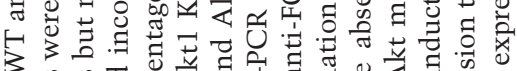

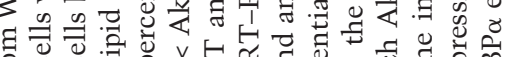

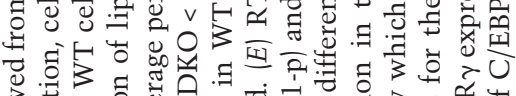

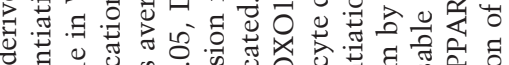

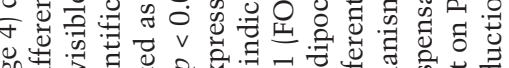

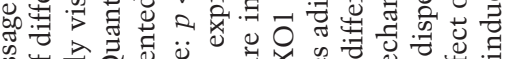
क्षे

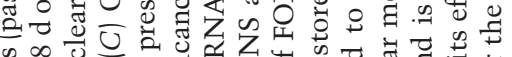

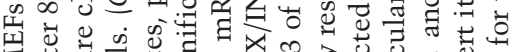

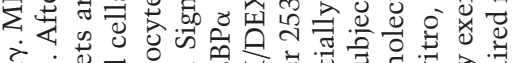

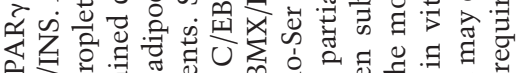

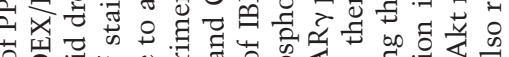
슬

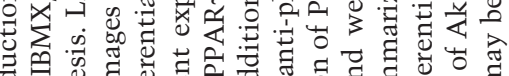

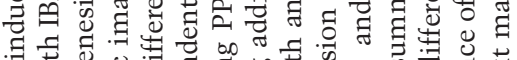
青然.

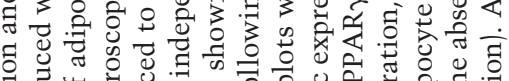

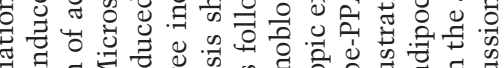

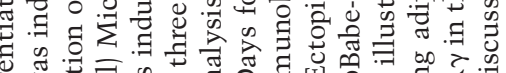

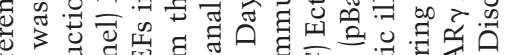

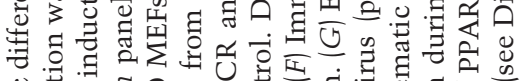

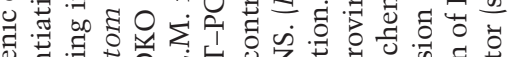
品

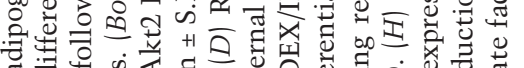

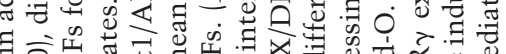

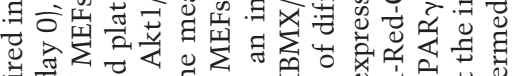

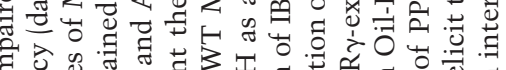
光

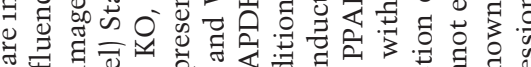
क

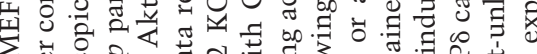

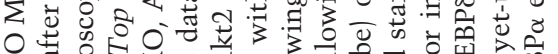

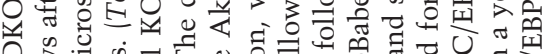

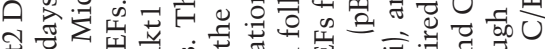

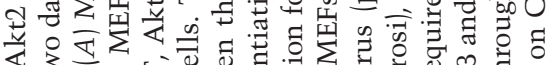
等

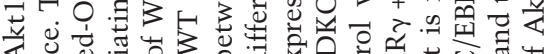
४

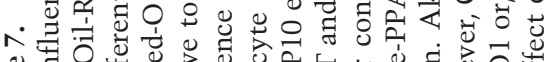

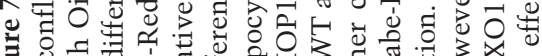

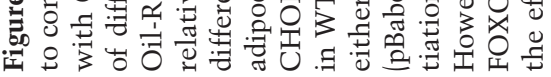


found, however, that DKO cells are not impaired in the ability to down-regulate CHOP10 expression when compared with WT cells (Fig. 7E, bottom panel).

It was recently shown that a constitutively active form of the forkhead transcription factor FOXO1 inhibits the induction of PPAR $\gamma$ expression and adipocyte differentiation in culture (Nakae et al. 2003). As FOXO1 is directly phosphorylated and inactivated by Akt, it is possible that the inability to induce PPAR $\gamma$ expression in Akt1/Akt2 DKO cells is due to an impaired ability to phosphorylate and inactivate FOXO1 in these cells. Indeed, we found that phosphorylation of FOXO1 by Akt is transiently induced $1 \mathrm{~d}$ after induction of differentiation in WT cells but that this phosphorylation is impaired in DKO cells (Fig. 7F).

We next examined whether ectopic expression of PPAR $\gamma$ restores differentiation in Akt1/Akt2 DKO MEFs. As shown in Figure 7G, the ectopic expression of PPAR $\gamma$ partially restores adipocyte differentiation in Akt1/Akt2 DKO MEFs, and this restoration is more profound when rosiglitazone, the ligand for $\operatorname{PPAR} \gamma$, is added to the cells.

Taken together, these results show that the failure of Akt1/Akt2 DKO cells to differentiate into adipocytes is mostly due to their inability to induce PPAR $\gamma$ expression, perhaps related to less efficient phosphorylation and inactivation of FOXO1. The implications of these results are summarized schematically in Figure $7 \mathrm{H}$.

\section{Discussion}

The studies presented here show that Akt1 and Akt2 are not required for successful completion of gestation in the mouse. However, Akt1/Akt2 DKO mice cannot survive after birth. The exact cause of death is not clear, but is likely respiratory failure because neonatal breathing is labored. The phenotype of Akt1/Akt2 DKO mice is strikingly similar to the phenotype of IGF-1 receptor $\mathrm{KO}$ mice (Liu et al. 1993). Both Akt1/Akt2 DKO mice and IGF-1 receptor KO mice display a severe growth deficiency; their weight at birth is about half of normal, and they both die immediately after birth. Both possess a thin epidermis caused primarily by impaired proliferation of keratinocytes, and both exhibit a delay in ossification. Finally, they both exhibit a decreased skeletal muscle tissues mass, although in the IGF-1 receptor $\mathrm{KO}$ mice, this was attributed to a decrease in the number of muscle cells, whereas in the Akt1/Akt2 DKO mice, this is attributed mostly to a decrease in individual cell size. These data suggest that IGF-1 receptor function during development is mostly dependent on Akt. Thus, even a reduced level of Akt activity is sufficient to unravel a full IGF-1 receptor KO phenotype. The IGF-1 receptor (IGFR) and insulin receptor (InsR) share the IRS proteins as downstream effectors that function upstream of Akt. Therefore, the Akt1/Akt2 DKO phenotype would be expected to reflect also the phenotype of InsR KO mice. However, it was reported that mice deficient in both IGFR and InsR are more severely growth-retarded and exhibit a slightly more severe phenotype than mice deficient in IGFR alone (Louvi et al. 1997). Nevertheless, it is possible that deficiency in both IGF-1 and insulin signaling is manifested by the impediment to adipogenesis observed inAkt1/Akt2 DKO mice, a phenomenon that has not been reported for the IGF-1 receptor KO mice.

Akt is essential for adipocyte differentiation and for the induction of PPAR $\gamma$ expression

Adipocyte differentiation is dependent on the sequential induction of transcription factors. The transcription factors $\mathrm{C} / \mathrm{EBP} \beta$ and $\mathrm{C} / \mathrm{EBP} \delta$ are induced first upon hormonal induction of differentiation. $\mathrm{C} / \mathrm{EBP} \beta$ and $\mathrm{C} / \mathrm{EBP} \delta$ are required to mediate the expression of $\mathrm{C} / \mathrm{EBP} \alpha$ and $\operatorname{PPAR} \gamma$, which can regulate the expression of each other (Rosen et al. 2000). PPAR $\gamma$ induces a large number of adipocyte-specific genes, and recent studies show that PPAR $\gamma$ is the most critical transcription factor required for adipogenesis (Rosen et al. 2002).

Although the transcription cascade leading to adipogenesis is well established, the upstream signaling pathways leading to activation of this cascade have not been clearly resolved. It is evident that insulin and IGF-1 receptors and their downstream effectors IRS1 and IRS2 are required for adipogenesis (Fasshauer et al. 2001; Miki et al. 2001), but it is not clear which downstream effectors of these signaling molecules are required for adipogenesis. There is, however, indirect evidence, through the use of pharmacological inhibitors, that PI3K is required (Miki et al. 2001). Here, we provide direct genetic evidence that the downstream effector of PI3K, Akt, is absolutely required for adipocyte differentiation and for the induction of PPAR $\gamma$ expression. Akt is required for the generation of BAT in the mouse and for in vitro differentiation of MEFs into adipocytes. Interestingly, Akt appears to be dispensable for the expression of $\mathrm{C} / \mathrm{EBP} \beta$ and $\mathrm{C} / \mathrm{EBP} \delta$, and the results imply that the expression of $\mathrm{C} / \mathrm{EBP} \beta$ and $\mathrm{C} / \mathrm{EBP} \delta$ is not sufficient to elicit induction of PPAR $\gamma$ expression during adipocyte differentiation. It appears that Akt as well as $\mathrm{C} / \mathrm{EBP} \beta$ and $\mathrm{C} / \mathrm{EBP} \delta$ are required for the induction of PPAR $\gamma$ expression. It has been suggested that the inactivation of FOXO1 is required for the clonal expansion prior to terminal differentiation (Nakae et al. 2003), and therefore Akt may exert its effect on adipocyte differentiation and PPAR $\gamma$ expression, at least in part, through phosphorylation and inactivation of FOXO1. Indeed, in vivo, although DKO preadipocytes are maintained in a proliferative state, their number is markedly reduced, suggesting that their rate of proliferation is attenuated. Likewise, inhibition of clonal expansion may contribute to the impediment of adipogenesis in Akt-null MEFs because Akt1 KO and Akt1/Akt2 DKO cells are also impaired with respect to proliferation (Kandel et al. 2002; data not shown). However, it is likely that Akt can affect adipogenesis at multiple levels. It was shown that mTOR activity is required for adipogenesis (Yeh et al. 1995; Gagnon et al. 2001), and thus the effect of Akt on mTOR can also contribute to adipogenesis. In addition, the effect of Akt on the translocation of the 
glucose transporter, GLUT4 (Cong et al. 1997), contributes to adipocyte function. Further studies are required to delineate the exact mechanisms by which Akt exerts its effects on adipocyte differentiation and induction of PPAR $\gamma$ expression.

\section{Akt can determine cell mass and is required for mTOR activity}

We show that skeletal muscle cells of Akt1/Akt2 DKO mice display a severe cellular atrophy and a decrease in cell size. This is consistent with previous studies implicating Akt in determining skeletal muscle hypertrophy (Bodine et al. 2001; Rommel et al. 2001; Fingar et al. 2002; Pallafacchina et al. 2002). It is worth noting that the number of myonuclei per each muscle fiber can also determine the size of muscle fibers (Roy et al. 1999). Thus, it is possible that the combined deletion of Akt1 and Akt2 may also reduce the number of myonuclei or impair the fusion of cells during formation of muscle fibers. Although we cannot completely exclude this possibility, it is unlikely to constitute the primary cause of atrophy because a significant decrease in precursor myoblast cell number would also markedly decrease the number of muscle fibers, which is not observed in the Akt1/Akt2 DKO mice.

Although it was previously shown that expression of activated Akt in mouse organs increases cell and organ size (Tuttle et al. 2001; Shioi et al. 2002), the results presented here establish for the first time genetic evidence that Akt is required for determining cell size in a mammalian organism. This is also consistent with genetic studies in Drosophila showing that the loss of Akt reduces cell size (Verdu et al. 1999; Scanga et al. 2000).

Because mTOR has been shown to determine cell size and Akt may determine cell size through the modulation of mTOR activity especially in skeletal muscles, we investigated the effect of Akt1 and Akt2 deficiency on mTOR activity. The intracellular activity of mTOR is determined mainly by the phosphorylation status of 4EBP1 and S6K1. The neonatal lethality of the Akt1/Akt2 DKO mice precludes us from analyzing Akt/mTOR interactions in skeletal muscles of DKO mice. We therefore analyzed this pathway in MEFs and found that, upon serum stimulation, there is a significant reduction in 4E-BP1 phosphorylation in DKO cells. Furthermore, there is a reduction in 4E-BP1 expression levels in DKO cells, probably to compensate for the inability to efficiently phosphorylate 4E-BP1. These results establish genetic evidence that Akt is required for mTOR-mediated phosphorylation of 4E-BP1.

It was shown recently that Akt activates mTOR through direct phosphorylation of TSC2 (Inoki et al. 2002; Manning et al. 2002; Potter et al. 2002). However, we could not always find a direct correlation between the reduction in mTOR activity, as measured by 4E-BP1 phosphorylation, and TSC2 phosphorylation in DKO cells, raising the possibility that there is another potential pathway by which Akt affects mTOR activity. Because it was shown that the intracellular levels of ATP
(Dennis et al. 2001) modulate mTOR activity, it is possible that a prospective alternate pathway may be related to the ability of Akt to increase intracellular ATP (Gottlob et al. 2001). Proliferating DKO cells exhibit reduced S6K1 phosphorylation similar to that observed with 4EBP1. However, unlike the case of 4E-BP1, S6K1 phosphorylation following serum stimulation is not impaired in DKO cells, suggesting that either S6K1 phosphorylation is more correlated with TSC2 phosphorylation, or that S6K1 is phosphorylated by an alternate mechanism following serum stimulation (Romanelli et al. 2002). Interestingly, genetic analyses in Drosophila show that the Drosophila S6K, dS6K, can function independently of Akt (Radimerski et al. 2002).

Taken together, our results establish that Akt is required for cell proliferation, cell growth, and differentiation in vivo. Previous analyses of mice deficient in either Akt1 or Akt2 (Chen et al. 2001; Cho et al. 2001a,b) identified distinct phenotypes, suggesting separate functions for Akt1 versus Akt2 in vivo. However, the different phenotypes of the individual Akt1- and Akt2-null mice could be also explained by relative tissue-specific expression. Thus, the diabetic phenotype observed specifically in Akt2-null mice may be due to the relatively higher level of Akt2 expression in insulin-responsive tissues. The data presented here strongly suggest that Akt1 and Akt2 functionally overlap in vivo, and that their contribution to the phenotypes observed in Akt1/Akt2 DKO mice is additive. For example, the deficiency of Akt1 by itself elicits only mild growth retardation (Chen et al. 2001; Cho et al. 2001b), whereas the deficiency of Akt2 is not sufficient to elicit growth retardation /Cho et al. 2001a) or can elicit only mild growth retardation in certain strain backgrounds (Garofalo et al. 2003). The combined deletion of Akt1 and Akt2, however, results in severe growth retardation, which suggests that this phenotype is unraveled only if Akt activity is reduced below a certain threshold and cannot be a manifestation of only one particular Akt isoform. Furthermore, analyses of $\mathrm{Akt1}^{+/-} / \mathrm{Akt2}^{-/-}$and $\mathrm{Akt1^{-/- }} / \mathrm{Akt2^{+/- }}$ littermates show that the relative contributions of Akt1 and Akt2 to the phenotypes described here is directly correlated to their relative level of expression in certain tissues. Thus, in the skin, where Akt1 is the predominantly expressed isoform, the contribution of Akt1 to skin development is higher than that of Akt2 (data not shown). On the other hand, Akt2 is expressed at a higher level than Akt1 in $\mathrm{BAT}$, and therefore the contribution of Akt2 to adipogenesis in vivo is predominant (data not shown). Likewise Akt1 contributes more significantly to adipocyte differentiation of MEFs in vitro because it is the predominantly expressed isoform in MEFs. Therefore, it is likely that the distinct observed phenotypes of the individual deletions and the combined deletions of the different Akt isoforms is a manifestation of a reduction in total Akt activity below a certain threshold in particular cell types and tissues.

One of the most prominent functions of Akt is to mediate cell survival. Indeed, adult Akt1-null mice display increased spontaneous apoptosis (Chen et al. 2001). 
However, no increase in spontaneous apoptosis was observed in DKO newborns and E18.5 embryos by TUNEL analysis, suggesting that Akt1 and Akt2 are not required for developmental apoptosis. It is possible, however, that in this respect, Akt3 compensates for both Akt1 and Akt2 during development, or that other compensatory mechanisms were activated. It is worth noting that Bcl2-deficient mice are viable despite widespread expression of Bcl-2 during mouse development, whereas the role of Bcl-2 in apoptosis is evident only in the adult (Veis et al. 1993). Thus, it is also possible that Akt plays a more active role in maintaining tissue homeostasis in the adult and in response to environmental stress than it does during development.

\section{Materials and methods}

\section{Generation of Akt1/Akt2 DKO mice}

Akt1-null mice have been described (Chen et al. 2001). Akt2null mice were generated by replacing $3.4 \mathrm{~kb}$ of the Akt2 genomic locus with a PGK-neo cassette. Three exons corresponding to base pairs 788-1047 of the murine Akt2 cDNA (U22445) were located within the 3.4-kb replaced region. Detailed analyses of the Akt2-null mice are described elsewhere (R.S. Garofalo, S.J. Orena, K. Rafidi, A.J. Torchia, J.L. Stock, A.L. Hildebrandt, T. Coskran, S.C. Black, D.J. Brees, J.R. Wicks, et al., in prep.). Akt1-null mice were crossed with Akt2-null mice to generate Akt1/Akt2 double-heterozygous mice, which were then intercrossed to generate Akt1/Akt2 DKO mice.

\section{Histological and anatomical analyses}

For histopathology, embryos were dissected from anesthetized females. Embryos and newborns were perfused, fixed in $4 \%$ paraformaldehyde overnight, then processed and embedded in paraffin. Sections $(5-7 \mu \mathrm{m})$ were stained with hematoxylin and eosin.

For immunohistochemistry, tissue sections were incubated at $95^{\circ} \mathrm{C}$ in $0.01 \mathrm{M}$ citric acid ( $\mathrm{pH}$ 6.0) for $30 \mathrm{~min}$, followed by a 20 -min cool-down. Sections were then treated with $0.3 \%$ hydrogen peroxide to block endogenous peroxides, then with $5 \%$ BSA in PBS to reduce nonspecific staining. Sections were incubated with primary antibodies overnight at $4^{\circ} \mathrm{C}$, followed by incubation with the biotinylated secondary antibody and avidin-biotin-complexes (ABC). Signals were visualized with diaminobenzidine. Some sections were lightly counterstained with hematoxylin. The primary antibodies included anti-PCNA (Santa Cruz Biotechnology), anti-K10 (BABCO), anti-K14 (Novocastre), and anti-filaggrin (BABCO). Biotin-conjugated secondary antibody kits, avidin-biotin complexes, and diaminobenzidine were purchased from Vector Laboratories.

The muscle fiber cross-sectional area and fiber diameter were measured from presternum and intercostal muscles, respectively, from heart-level cross sections of neonatal mice. Diaphragm thickness measurements were taken from liver-level cross sections. Digitized muscle images were taken with a Leica DM IRB microscope equipped with an MTI CCD camera with Image Pro Plus software and analyzed by the J image analysis program. The size and diameter of individual cells were determined by the number of pixels within manually outlined fiber boundaries or the lines across the diameter of each muscle fiber. Multiple samples (20 cells per sample) were analyzed.

Skeletal analysis and staining with Alcian blue GX (Sigma) and Alizarin red S (Fluka) were performed as previously described (Menegola et al. 2001).

\section{Cell culture}

Primary embryonic fibroblasts were harvested from E14.5 mouse embryos and grown in DMEM with $10 \%$ FCS (Hyclone). The retroviral vector pBabepuro-PPAR $\gamma$ was provided by Bruce Spiegelman (Harvard Medical School, Boston, MA), and retrovirus generation and infection were performed as previously described (Gottlob et al. 2001). The induction of adipogenic differentiation was accomplished as previously described (Miki et al. 2001), with minor modifications. Briefly, cells were cultured at $37^{\circ} \mathrm{C}$ in $\alpha$-modified Eagle's medium ( $\alpha$ MEM; Bio-Whittaker) supplemented with $10 \%$ heat-inactivated FCS (Hyclone) and 2 $\mathrm{mM}$ glutamine (Bio-Whittaker). Cells were plated and propagated to confluence. Two days later (day 0), medium was replaced with a standard differentiation-induction medium containing $0.5 \mathrm{mM}$ IBMX (Sigma), $1 \mu \mathrm{M}$ DEX (Sigma), $5 \mu \mathrm{g} / \mathrm{mL}$ insulin (Sigma), 10\% FCS, and $2 \mathrm{mM}$ glutamine. This medium was renewed every other day. After $8 \mathrm{~d}$, cytoplasmic lipid accumulation was observed by light microscopy with or without Oil-Red-O staining, which was performed as follows: cells were washed with phosphate-buffered saline (PBS), fixed with $4 \%$ paraformaldehyde at $4{ }^{\circ} \mathrm{C}$ overnight, and then stained with $60 \%$ filtered Oil-Red-O stock solution [0.3 g of Oil-Red-O (Sigma) in $100 \mathrm{~mL}$ of isopropanol] at room temperature for $30 \mathrm{~min}$. Fixed cells were washed three times with water and visualized. For quantitative analysis of the Oil-Red-O staining, the Oil-Red-O was extracted with $1 \mathrm{~mL}$ of isopropanol and estimated by spectroscopy at $490 \mathrm{~nm}$. Serial dilutions of $0,5,10,20,40$, and $80 \mathrm{~mL}$ of $60 \%$ filtered Oil-Red-O stock solution in $1 \mathrm{~mL}$ of isopropanol were used as the standard. To prepare RNA for RT-PCR, cells were harvested on day $0,2,5$, and 8 following induction of differentiation.

\section{RNA analysis}

Total RNA was extracted from MEFs using the Absolutely RNA RT-PCR Miniprep Kit (Stratagene) according to the manufacturer's instructions. The concentration and purity of the RNA samples were estimated by UV spectroscopy at 260 and $280 \mathrm{~nm}$, and integrity was confirmed by electrophoresis in $1 \%$ agarose gels stained with ethidium bromide.

For RT-PCR analysis, first-strand cDNA was synthesized from $1 \mu \mathrm{g}$ of total RNA using the Superscript First-Strand Synthesis System for RT-PCR (Invitrogen). The resultant cDNA was used for PCR amplification with specific (test) or GAPDH (positive control) primers. Specific primer sequences were selected based on previously described principles (Peng et al. 2001). The same primer concentrations were used for Akt1, $\mathrm{Akt} 2$, and Akt3. Other parameters were empirically determined to achieve specific, noncompetitive amplification of comparable levels of PCR product. The primer sequences and optimal conditions used to amplify GAPDH, Akt1, Akt2, Akt3, PPAR $\gamma$, $\mathrm{C} / \mathrm{EBP} \alpha, \mathrm{C} / \mathrm{EBP} \beta, \mathrm{C} / \mathrm{EBP} \delta$, and $\mathrm{CHOP} 10$ are available upon request.

\section{Protein analysis}

MEFs were grown in DMEM with $10 \%$ FCS. Cell lysates were prepared in $200 \mu \mathrm{L}$ of lysis buffer $(20 \mathrm{mM}$ Tris- $\mathrm{HCl}$ at $\mathrm{pH} 7.5$, $100 \mathrm{mM} \mathrm{KCl}, 20 \mathrm{mM} \beta$-glycerophosphate, $1 \mathrm{mM}$ DTT, $250 \mu \mathrm{M}$ $\mathrm{NA}_{3} \mathrm{VO}_{4}, 10 \mathrm{mM} \mathrm{NaF}, 1 \mathrm{mM}$ EDTA, 1 mM EGTA, $1 \mathrm{mM}$ PMSF, $10 \mathrm{mM}$ Na-pyrophosphate, $10 \mathrm{nM}$ Okadaic acid, protease inhibitor cocktail, complete; Boehringer Ingelheim) with thawfreeze-cycle extraction. Proteins were separated by SDS-PAGE on $8 \%$ or $15 \%$ (for $4 \mathrm{E}-\mathrm{BP} 1$ ) gels, and immunoblotting was performed as previously described (Gingras et al. 1998). Antibodies 
specific for Akt1 and Akt2 were from Upstate Biotechnology. Antibodies against pan-Akt, phospho-Ser 65 of 4E-BP1, phospho-Thr 389 of S6K1, phospho-Thr 1462 of TSC2, phospho-Ser 253 of FOXO1, S6K1, and FOXO1 were from Cell Signaling Technology. Antibodies against 4E-BP1 were provided by Nahum Sonenberg (McGill University, Montreal, Canada).

For immunoprecipitation, lysates were prepared as described above except that $1 \%$ NP-40 and $10 \%$ glycerol were added to the lysis buffer. Lysates were incubated overnight with anti-TSC2 (diluted 1:200; Santa Cruz Biotechnology), followed by a 2-h incubation with a slurry of protein A/G Plus-agarose affinity gel (Santa Cruz Biotechnology). Immune complexes were then washed five times with wash buffer $(20 \mathrm{mM}$ HEPES at $\mathrm{pH} 7.5$, $150 \mathrm{mM} \mathrm{NaCl}, 50 \mathrm{mM} \mathrm{NaF}, 1 \mathrm{mM}$ EDTA, $1 \%$ NP-40, $1 \mathrm{mM}$ DTT, $50 \mathrm{mM} \beta$-glycerophosphate, and protease inhibitor cocktail) and denatured in $2 \times$ Laemmli sample buffer. Proteins were separated by SDS-PAGE on $6 \%$ gels and were transferred to a nitrocellulose membrane for immunoblotting with anti-Akt-pS/T substrate (Cell Signaling Technology) and anti-TSC2 (Santa Cruz Biotechnology).

\section{Acknowledgments}

We thank Yongmei Luo and Sophia Chin for their excellent technical assistance, and Veronica Stellmack for advice. This work was supported by NIH grants AG16927 and CA90764 and by a grant from Pfizer to N.H.

The publication costs of this article were defrayed in part by payment of page charges. This article must therefore be hereby marked "advertisement" in accordance with 18 USC section 1734 solely to indicate this fact.

\section{References}

Altomare, D.A., Guo, K., Cheng, J.Q., Sonoda, G., Walsh, K., and Testa, J.R. 1995. Cloning, chromosomal localization and expression analysis of the mouse Akt2 oncogene. Oncogene 11: $1055-1060$.

Altomare, D.A., Lyons, G.E., Mitsuuchi, Y., Cheng, J.Q., and Testa, J.R. 1998. Akt2 mRNA is highly expressed in embryonic brown fat and the AKT2 kinase is activated by insulin. Oncogene 116: 2407-2411.

Barak, Y., Nelson, M.C., Ong, E.S., Jones, Y.Z., Ruiz-Lozano, P., Chien, K.R., Koder, A., and Evans, R.M. 1999. PPAR $\gamma$ is required for placental, cardiac, and adipose tissue development. Mol. Cell 4: 585-595.

Bodine, S.C., Stitt, T.N., Gonzalez, M., Kline, W.O., Stover, G.L., Bauerlein, R., Zlotchenko, E., Scrimgeour, A., Lawrence, J.C., Glass, D.J., et al. 2001. Akt/mTOR pathway is a crucial regulator of skeletal muscle hypertrophy and can prevent muscle atrophy in vivo. Nat. Cell Biol. 3: 1014-1019.

Brazil, D.P. and Hemmings, B.A. 2001. Ten years of protein kinase B signalling: A hard Akt to follow. Trends Biochem. Sci. 26: 657-664.

Britton, J.S., Lockwood, W.K., Li, L., Cohen, S.M., and Edgar, B.A. 2002. Drosophila's insulin/PI3-kinase pathway coordinates cellular metabolism with nutritional conditions. Dev. Cell 2: 239-249.

Brodbeck, D., Cron, P., and Hemmings, B.A. 1999. A human protein kinase $\mathrm{B} \gamma$ with regulatory phosphorylation sites in the activation loop and in the C-terminal hydrophobic domain. J. Biol. Chem. 274: 9133-9136.

Cantley, L.C. and Neel, B.G. 1999. New insights into tumor suppression: PTEN suppresses tumor formation by restraining the phosphoinositide 3-kinase/AKT pathway. Proc. Natl. Acad. Sci. 96: 4240-4245.
Chen, W.S., Xu, P.Z., Gottlob, K., Chen, M.L., Sokol, K., Shiyanova, T., Roninson, I., Weng, W., Suzuki, R., Tobe, K., et al. 2001. Growth retardation and increased apoptosis in mice with homozygous disruption of the Akt1 gene. Genes \& Dev. 15: 2203-2208.

Cho, H., Mu, J., Kim, J.K., Thorvaldsen, J.L., Chu, Q., Crenshaw III, E.B., Kaestner, K.H., Bartolomei, M.S., Shulman, G.I., and Birnbaum, M.J. 2001a. Insulin resistance and a diabetes mellitus-like syndrome in mice lacking the protein kinase Akt2 (РKB $\beta$ ). Science 292: 1728-1731.

Cho, H., Thorvaldsen, J.L., Chu, Q., Feng, F., and Birnbaum, M.J. 2001b. Akt $1 / \mathrm{PKB} \alpha$ is required for normal growth but dispensable for maintenance of glucose homeostasis in mice. J. Biol. Chem. 276: 38349-38352.

Cong, L.N., Chen, H., Li, Y., Zhou, L., McGibbon, M.A., Taylor, S.I., and Quon, M.J. 1997. Physiological role of Akt in insulin-stimulated translocation of GLUT4 in transfected rat adipose cells. Mol. Endocrinol. 11: 1881-1890.

Datta, S.R., Brunet, A., and Greenberg, M.E. 1999. Cellular survival: A play in three Akts. Genes \& Dev. 13: 2905-2927.

Dennis, P.B., Jaeschke, A., Saitoh, M., Fowler, B., Kozma, S.C., and Thomas, G. 2001. Mammalian TOR: A homeostatic ATP sensor. Science 294: 1102-1105.

Dufner, A. and Thomas, G. 1999. Ribosomal S6 kinase signaling and the control of translation. Exp. Cell Res. 253: 100-109.

Edgar, B.A. 1999. From small flies come big discoveries about size control. Nat. Cell Biol. 1: E191-E193.

Fasshauer, M., Klein, J., Kriauciunas, K.M., Ueki, K., Benito, M., and Kahn, C.R. 2001. Essential role of insulin receptor substrate 1 in differentiation of brown adipocytes. Mol. Cell. Biol. 21: 319-329.

Finch, C.E. and Ruvkun, G. 2001. The genetics of aging. Annu. Rev. Genomics Hum. Genet. 2: 435-462.

Fingar, D.C., Salama, S., Tsou, C., Harlow, E., and Blenis, J. 2002. Mammalian cell size is controlled by $\mathrm{mTOR}$ and its downstream targets S6K1 and 4EBP1/eIF4E. Genes \& Dev. 16: $1472-1487$.

Gagnon, A., Lau, S., and Sorisky, A. 2001. Rapamycin-sensitive phase of 3T3-L1 preadipocyte differentiation after clonal expansion. J. Cell Physiol. 189: 14-22.

Garofalo, R.S., Orena, S.J., Rafidi, K., Torchia, A.J., Stock, J.L., Hildebrandt, A.L., Coskran, T., Black, S.C., Brees, D.J., Wicks, J.R., et al. 2003. Mice lacking Akt2/PK $\beta$ are growth deficient, lipoatrophic and develop severe diabetes. J. Clin. Invest. (in press).

Gingras, A.C., Kennedy, S.G., O'Leary, M.A., Sonenberg, N., and Hay, N. 1998. 4E-BP1, a repressor of mRNA translation, is phosphorylated and inactivated by the Akt(PKB) signaling pathway. Genes \& Dev. 12: 502-513.

Gingras, A.C., Gygi, S.P., Raught, B., Polakiewicz, R.D., Abraham, R.T., Hoekstra, M.F., Aebersold, R., and Sonenberg, N. 1999. Regulation of 4E-BP1 phosphorylation: A novel twostep mechanism. Genes \& Dev. 13: 1422-1437.

Gingras, A.C., Raught, B., and Sonenberg, N. 2001. Regulation of translation initiation by FRAP/mTOR. Genes \& Dev. 15: 807-826.

Gottlob, K., Majewski, N., Kennedy, S., Kandel, E.S., Robey, R.B., and Hay, N. 2001. Inhibition of early apoptotic events by Akt/PKB is dependent on the first committed step of glycolysis and mitochondrial hexokinase. Genes \& Dev. 15: 1406-1418.

Hu, E., Tontonoz, P., and Spiegelman, B.M. 1995. Transdifferentiation of myoblasts by the adipogenic transcription factors PPAR $\gamma$ and C/EBP $\alpha$. Proc. Natl. Acad. Sci. 92: 9856-9860.

Inoki, K., Li, Y., Zhu, T., Wu, J., and Guan, K.L. 2002. TSC2 is phosphorylated and inhibited by Akt and suppresses mTOR signalling. Nat. Cell Biol. 4: 648-657. 
Kandel, E.S. and Hay, N. 1999. The regulation and activities of the multifunctional serine/threonine kinase Akt/PKB. Exp. Cell Res. 253: 210-229.

Kandel, E.S., Skeen, J., Majewski, N., Di Cristofano, A., Pandolfi, P.P., Feliciano, C.S., Gartel, A., and Hay, N. 2002. Activation of Akt/protein kinase $B$ overcomes a $G_{2} / M$ cell cycle checkpoint induced by DNA damage. Mol. Cell. Biol. 22: 7831-7841.

Kozma, S.C. and Thomas, G. 2002. Regulation of cell size in growth, development and human disease: PI3K, PKB and S6K. Bioessays 24: 65-71.

Kubota, N., Terauchi, Y., Miki, H., Tamemoto, H., Yamauchi, T., Komeda, K., Satoh, S., Nakano, R., Ishii, C., Sugiyama, T., et al. 1999. PPAR $\gamma$ mediates high-fat diet-induced adipocyte hypertrophy and insulin resistance. Mol. Cell 4: 597-609.

Lawlor, M.A. and Alessi, D.R. 2001. PKB/Akt: A key mediator of cell proliferation, survival and insulin responses? I. Cell Sci. 114: 2903-2910.

Liu, J., Baker, J., Perkins, A., Robertson, E., and Efstratiadis, A. 1993. Mice carrying null mutations of the genes encoding insulin-like growth factor I (Igf-1) and type 1 IGF receptor (Igf1r). Cell 75: 59-72.

Louvi, A., Accili, D., and Efstratiadis, A. 1997. Growth-promoting interaction of IGF-II with the insulin receptor during mouse embryonic development. Dev. Biol. 189: 33-48.

Manning, B.D., Tee, A.R., Logsdon, M.N., Blenis, J., and Cantley, L.C. 2002. Identification of the tuberous sclerosis complex-2 tumor suppressor gene product tuberin as a target of the phosphoinositide 3-kinase/akt pathway. Mol. Cell 10: $151-162$.

Menegola, E., Broccia, M.L., and Giavini, E. 2001. Atlas of rat fetal skeleton double stained for bone and cartilage. Teratology 64: 125-133.

Miki, H., Yamauchi, T., Suzuki, R., Komeda, K., Tsuchida, A., Kubota, N., Terauchi, Y., Kamon, J., Kaburagi, Y., Matsui, J., et al. 2001. Essential role of insulin receptor substrate 1 (IRS1) and IRS-2 in adipocyte differentiation. Mol. Cell. Biol. 21: 2521-2532.

Muller, M., Jasmin, J.R., Monteil, R.A., and Loubiere, R. 1991. Embryology of the hair follicle. Early Hum. Dev. 26: 159-166.

Nakae, J., Kitamura, T., Kitamura, Y., Biggs, W.H., Arden, K.C., and Accili, D. 2003. The forkhead transcription factor foxol regulates adipocyte differentiation. Dev. Cell 4: 119-129.

Nakatani, K., Sakaue, H., Thompson, D.A., Weigel, R.J., and Roth, R.A. 1999. Identification of a human Akt3 (protein kinase $\mathrm{B} \gamma$ ) which contains the regulatory serine phosphorylation site. Biochem. Biophys. Res. Commun. 257: 906-910.

Pallafacchina, G., Calabria, E., Serrano, A.L., Kalhovde, J.M., and Schiaffino, S. 2002. A protein kinase B-dependent and rapamycin-sensitive pathway controls skeletal muscle growth but not fiber type specification. Proc. Natl. Acad. Sci. 99: 9213-9218.

Peng, X.D., Park, S., Gadelha, M.R., Coschigano, K.T., Kopchick, J.J., Frohman, L.A., and Kineman, R.D. 2001. The growth hormone $(\mathrm{GH})$-axis of $\mathrm{GH}$ receptor/binding protein gene-disrupted and metallothionein-human GH-releasing hormone transgenic mice: Hypothalamic neuropeptide and pituitary receptor expression in the absence and presence of GH feedback. Endocrinology 142: 1117-1123.

Potter, C.J., Pedraza, L.G., and Xu, T. 2002. Akt regulates growth by directly phosphorylating Tsc2. Nat. Cell Biol. 4: 658-665.

Radimerski, T., Montagne, J., Rintelen, F., Stocker, H., van Der Kaay, J., Downes, C.P., Hafen, E., and Thomas, G. 2002. dS6K-regulated cell growth is $\mathrm{dPKB} / \mathrm{dPI} / 3 / \mathrm{K}$-independent, but requires dPDK1. Nat. Cell Biol. 4: 251-255.
Romanelli, A., Dreisbach, V.C., and Blenis, J. 2002. Characterization of phosphatidylinositol 3-kinase-dependent phosphorylation of the hydrophobic motif site Thr389 in p70 S6 kinase 1 (S6K1). J. Biol. Chem. 277: 40281-40289.

Rommel, C., Bodine, S.C., Clarke, B.A., Rossman, R., Nunez, L., Stitt, T.N., Yancopoulos, G.D., and Glass, D.J. 2001. Mediation of IGF-1-induced skeletal myotube hypertrophy by PI/3)K/Akt/mTOR and PI/3/K/Akt/GSK3 pathways. Nat. Cell Biol. 3: 1009-1013.

Ron, D. and Habener, J.F. 1992. CHOP, a novel developmentally regulated nuclear protein that dimerizes with transcription factors C/EBP and LAP and functions as a dominant-negative inhibitor of gene transcription. Genes \& Dev. 6: 439-453.

Rosen, E.D. and Spiegelman, B.M. 2001. PPAR $\gamma$ : A nuclear regulator of metabolism, differentiation, and cell growth. J. Biol. Chem. 276: 37731-37734.

Rosen, E.D., Sarraf, P., Troy, A.E., Bradwin, G., Moore, K., Milstone, D.S., Spiegelman, B.M., and Mortensen, R.M. 1999. PPAR $\gamma$ is required for the differentiation of adipose tissue in vivo and in vitro. Mol. Cell 4: 611-617.

Rosen, E.D., Walkey, C.J., Puigserver, P., and Spiegelman, B.M. 2000. Transcriptional regulation of adipogenesis. Genes \& Dev. 14: 1293-1307.

Rosen, E.D., Hsu, C.H., Wang, X., Sakai, S., Freeman, M.W., Gonzalez, F.J., and Spiegelman, B.M. 2002. C/EBP $\alpha$ induces adipogenesis through PPAR $\gamma$ : A unified pathway. Genes \& Dev. 16: 22-26.

Roy, R.R., Monke, S.R., Allen, D.L., and Edgerton, V.R. 1999. Modulation of myonuclear number in functionally overloaded and exercised rat plantaris fibers. J. Appl. Physiol. 87: 634-642.

Scanga, S.E., Ruel, L., Binari, R.C., Snow, B., Stambolic, V., Bouchard, D., Peters, M., Calvieri, B., Mak, T.W., Woodgett, J.R., et al. 2000. The conserved PI3'K/PTEN/Akt signaling pathway regulates both cell size and survival in Drosophila. Oncogene 19: 3971-3977.

Shioi, T., McMullen, J.R., Kang, P.M., Douglas, P.S., Obata, T., Franke, T.F., Cantley, L.C., and Izumo, S. 2002. Akt/protein kinase B promotes organ growth in transgenic mice. Mol. Cell. Biol. 22: 2799-2809.

Simpson, L. and Parsons, R. 2001. PTEN: Life as a tumor suppressor. Exp. Cell Res. 264: 29-41.

Tanaka, T., Yoshida, N., Kishimoto, T., and Akira, S. 1997. Defective adipocyte differentiation in mice lacking the C/EBP $\beta$ and/or C/EBP $\delta$ gene. EMBO J. 16: 7432-7443.

Tontonoz, P., Hu, E., and Spiegelman, B.M. 1994. Stimulation of adipogenesis in fibroblasts by PPAR $\gamma 2$, a lipid-activated transcription factor. Cell 79: 1147-1156.

Tuttle, R.L., Gill, N.S., Pugh, W., Lee, J.P., Koeberlein, B., Furth, E.E., Polonsky, K.S., Naji, A., and Birnbaum, M.J. 2001. Regulation of pancreatic $\beta$-cell growth and survival by the serine/ threonine protein kinase Akt1/PKB $\alpha$. Nat. Med. 7: 1133-1137.

Veis, D.J., Sorenson, C.M., Shutter, J.R., and Korsmeyer, S.J. 1993. Bcl-2-deficient mice demonstrate fulminant lymphoid apoptosis, polycystic kidneys, and hypopigmented hair. Cell 75: 229-240.

Verdu, J., Buratovich, M.A., Wilder, E.L., and Birnbaum, M.J. 1999. Cell-autonomous regulation of cell and organ growth in Drosophila by Akt/PKB. Nat. Cell Biol. 1: 500-506.

Walker, K.S., Deak, M., Paterson, A., Hudson, K., Cohen, P., and Alessi, D.R. 1998. Activation of protein kinase B $\beta$ and $\gamma$ isoforms by insulin in vivo and by 3 -phosphoinositide-dependent protein kinase-1 in vitro: Comparison with protein kinase B $\alpha$. Biochem. J. 331: 299-308.

Yeh, W.C., Bierer, B.E., and McKnight, S.L. 1995. Rapamycin inhibits clonal expansion and adipogenic differentiation of 3T3-L1 cells. Proc. Nat1. Acad. Sci. 92: 11086-11090. 


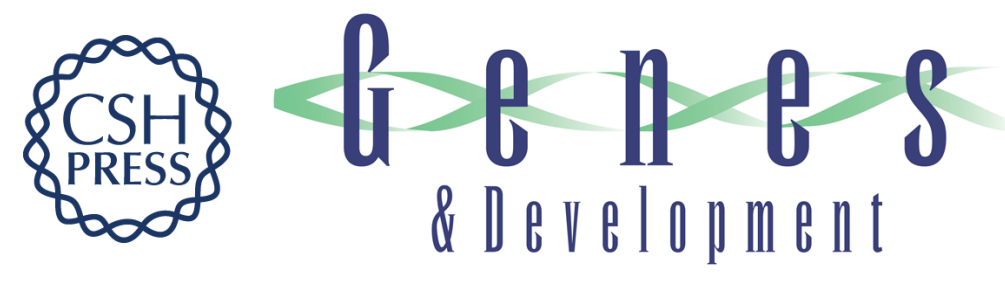

\section{Dwarfism, impaired skin development, skeletal muscle atrophy, delayed bone development, and impeded adipogenesis in mice lacking Akt1 and Akt2}

Xiao-ding Peng, Pei-Zhang Xu, Mei-Ling Chen, et al.

Genes Dev. 2003, 17:

Access the most recent version at doi:10.1101/gad.1089403

\section{References This article cites 58 articles, 25 of which can be accessed free at: http://genesdev.cshlp.org/content/17/11/1352.full.html\#ref-list-1}

License

Email Alerting

Service

Receive free email alerts when new articles cite this article - sign up in the box at the top right corner of the article or click here.

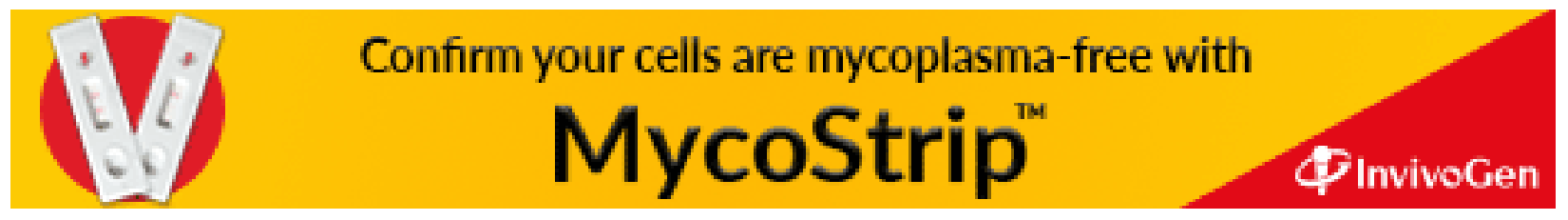

